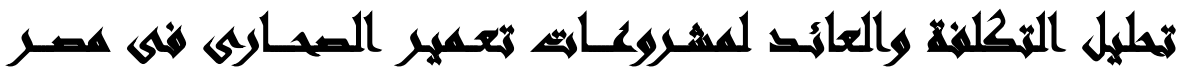

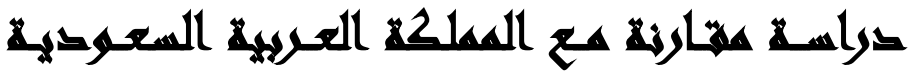

\section{[1 $\leqslant]$}

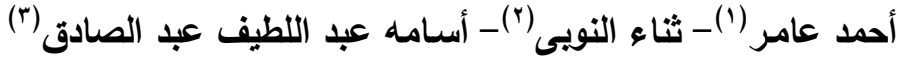

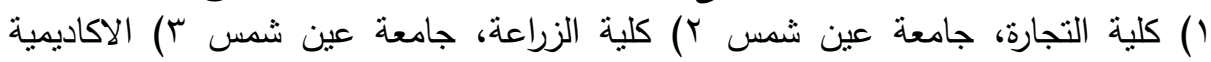
العربية للعلوم المُّتقدمة والتكنولوجيا

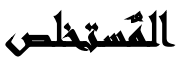

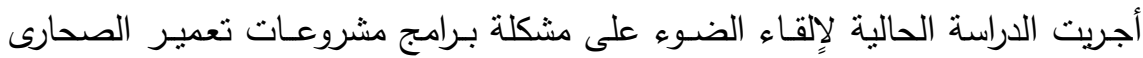

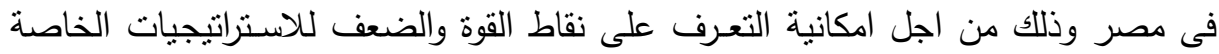

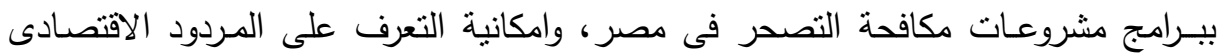

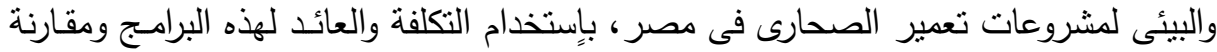

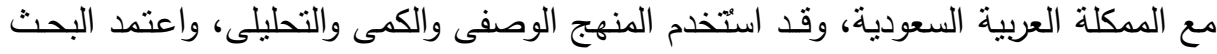

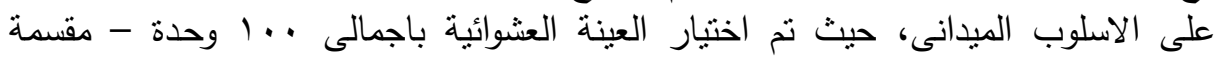

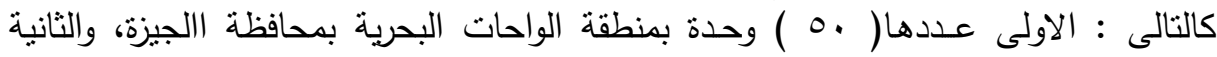

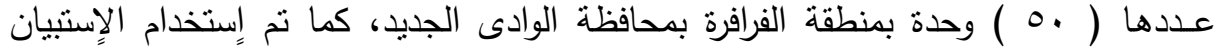

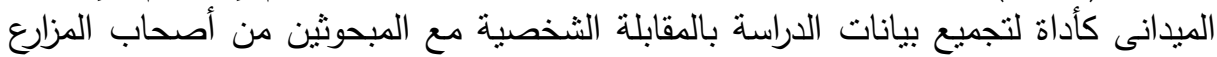

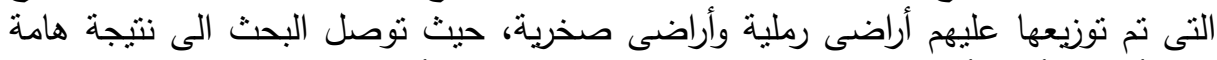

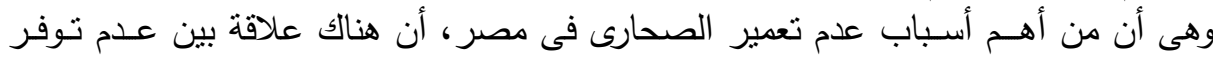

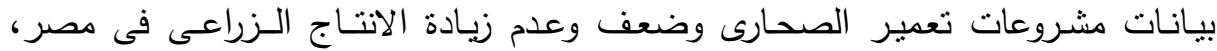

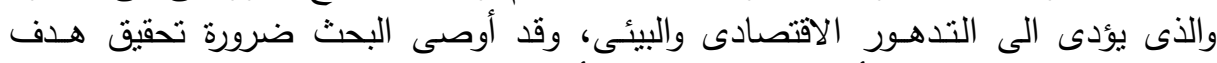

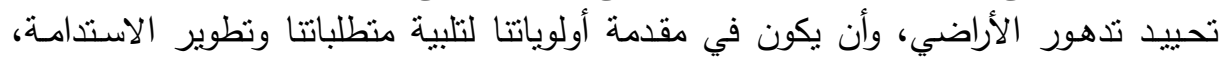

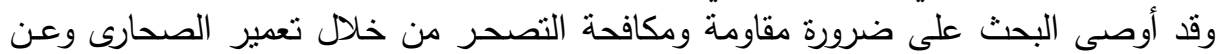

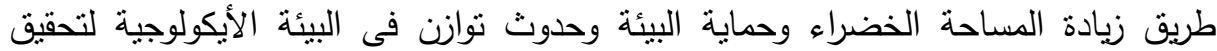

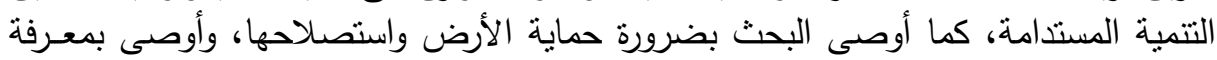

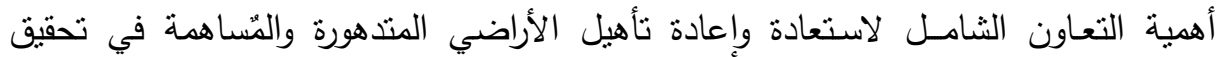

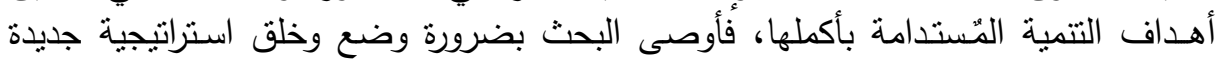

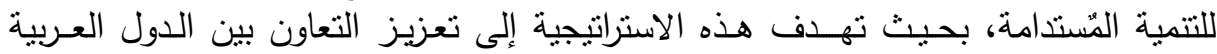

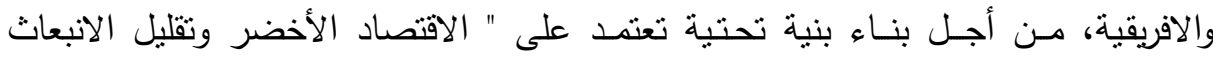

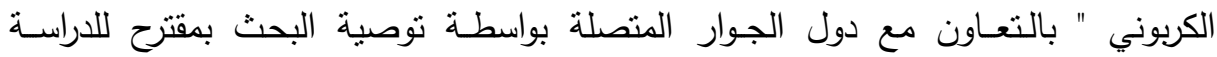

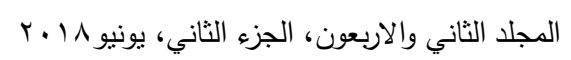


الحالية وهى ضرورة " التعاون العربى الافريقى المُّتـدام" والـذى أطلق عليه البحـث . "Sustainable Arab-African Cooperation " - ( SAAC)

\section{Mastion}

تُعـد قضية الأرض مـن أهـم القضـايـا العامة في مرحلة أهـداف التتمية المُّــدامة

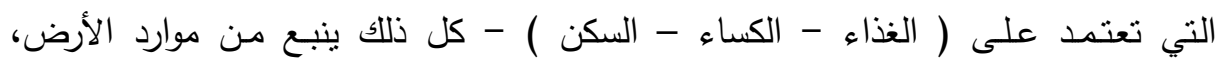
ولتحقيق هدف " لئلا يتخلف أحد عن الركب" المتفق عليه في أهداف التتمية المستدامة

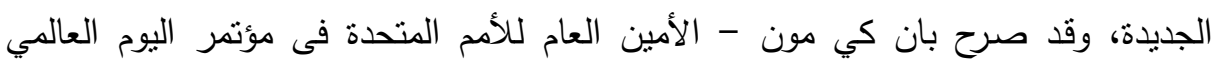
لمكافحة التصحر والجفاف عام 10 ب - تحت شعار 'تحقيق الأمن الغذائي من خلال النظم الغذائية المستدامة، حيث يوجد ما يقرب من 0، امليار شخص يعيشون في مناطق متدهورة

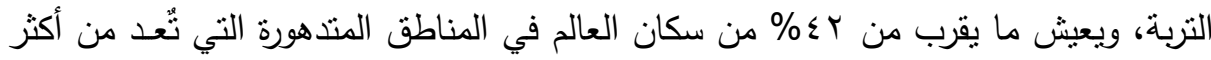

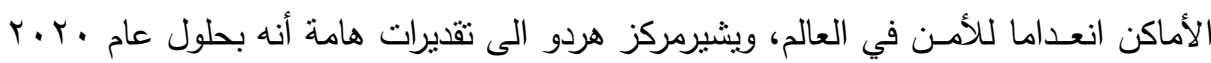
سيهاجر نحو ـ مليون نسمة من المناطق المنصحرة في أفريقيا جنوب الصحراء الكبري نحو

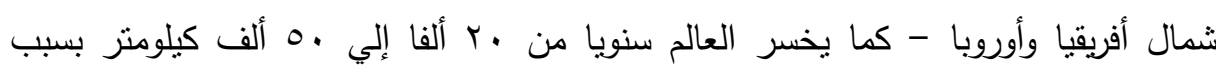

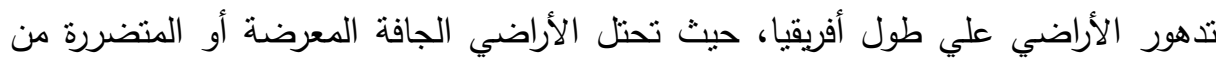
خطر التصحر نسبة r؟٪ من الإقليم، ومن المنوقع أن تفقد أفريقيا ثلثي الأراضي الزراعية

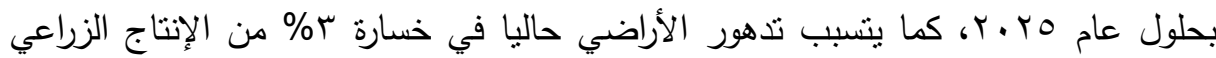

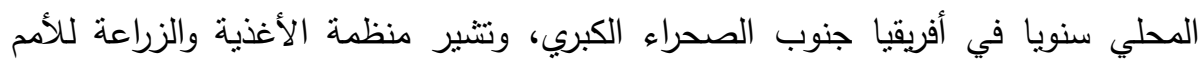

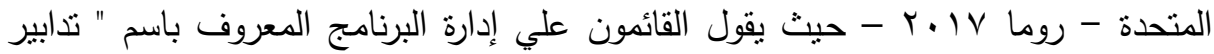

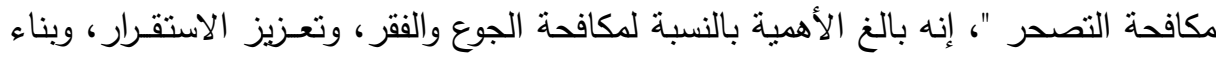

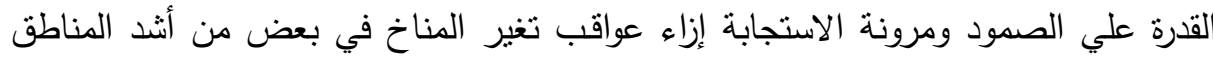

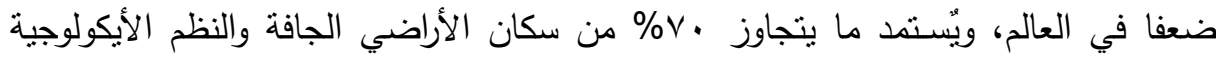

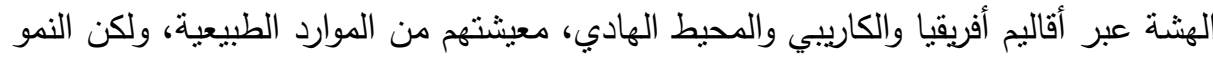

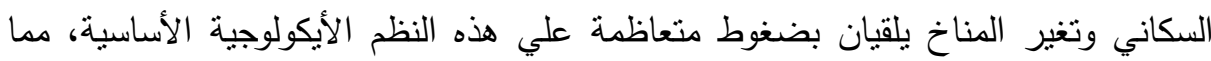
يفاقم من تدهور الأراضي والتصحر بمناطق تقع فعليا تحت طائلة الاستغلال الجائر علي نحو لإنير 
متزايد - لذا يجب ادراج المجالات البرنامجية التى تعهل على تدعيـم قاعدة المعرفة

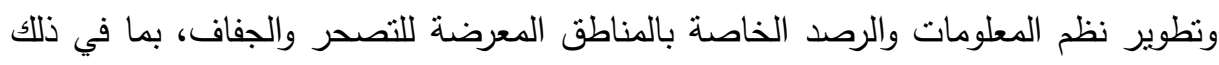

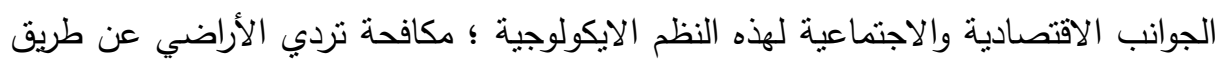

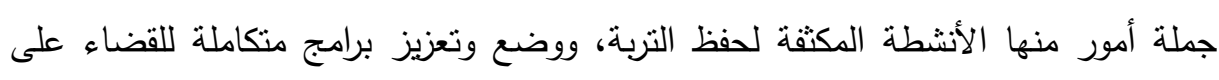
الفقر وتعزيز النظم البديلة لكسب العيش في المناطق المعرضة للتصحر؛ ووضعت التهب هيئة

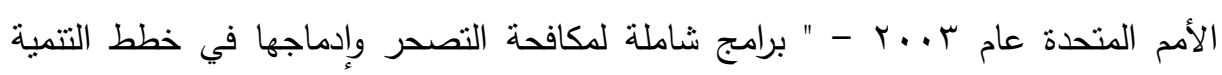
القومية، والتخطيط القومى في مجال حماية البيئة ؛ وكذلك وضع مخططات شاملة للتأهب

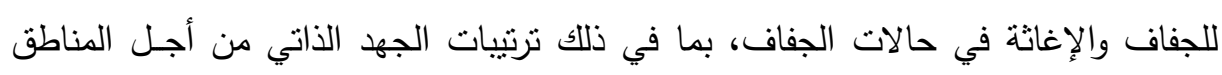

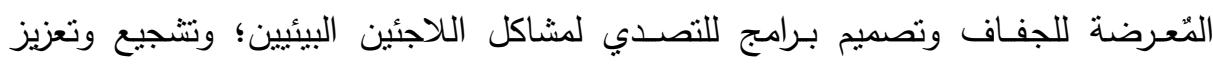

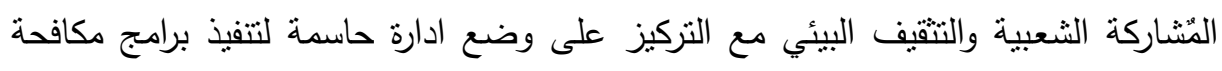
التصحر وإدارة آتـار الجفاف والتعديات على الاراضى الزراعية وحماية البيئة والموارد

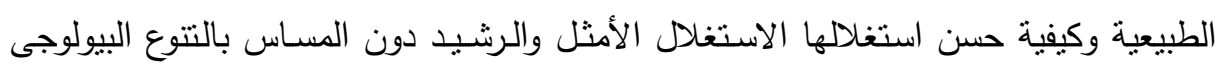

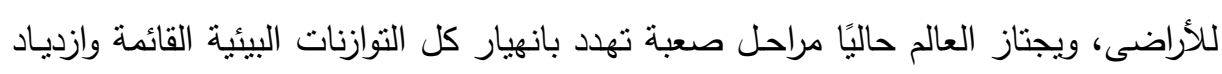

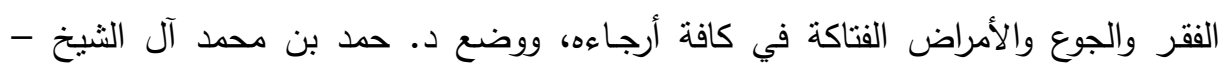

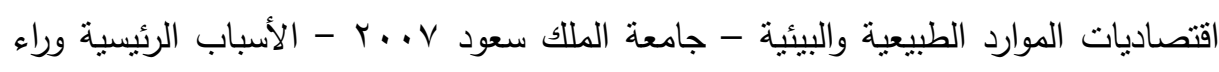
هذه الوضعية التي تتذر بالخطر إلى التدهور والنلوث المستمرين للموارد الطبيعية والبيئية وإلى الى التئية

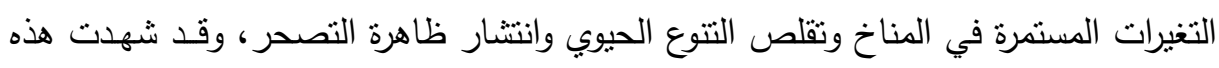
الظاهرة انتشارًا واسعًا في الوطن العربي على وجه الخصوص بسبب الإفراط في استغلال

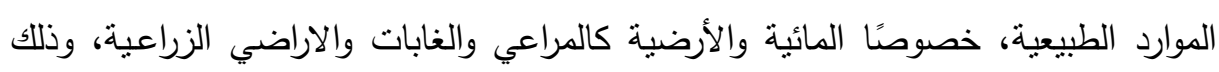
طوال فترات عديدة، ومما زاد في اتساع رقعة التصحر في البلاد العربية هشاشة النظم البيئية

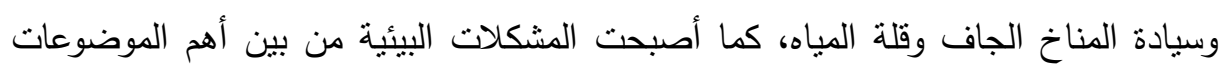

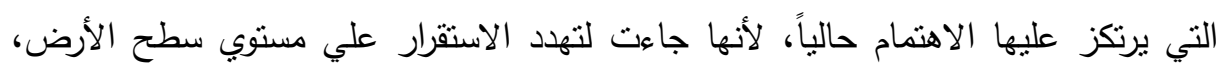

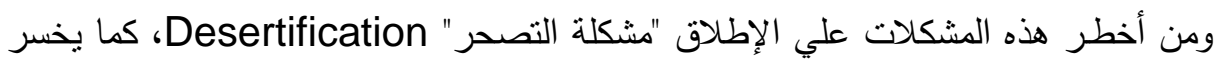

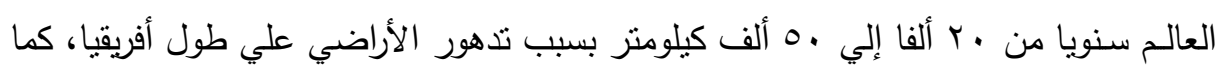

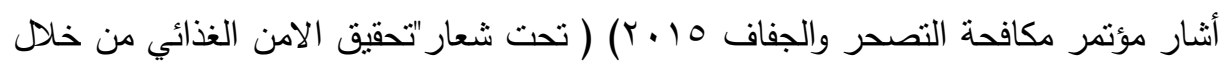

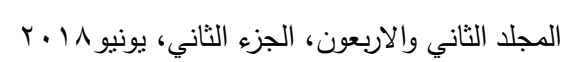


النظم الغذائيه المُّتدامة ) إلى أنه تحتل الأراضي الجافة المُّرضة أو المتضررة من خطر

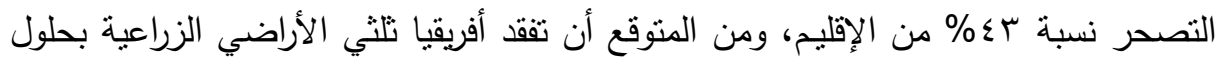

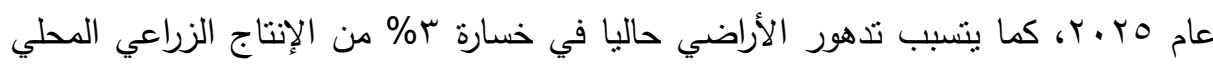

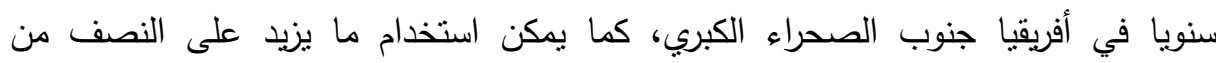

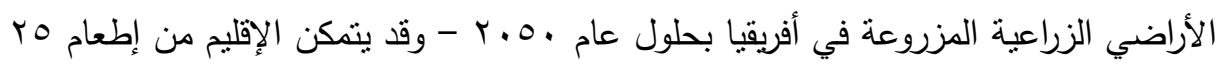

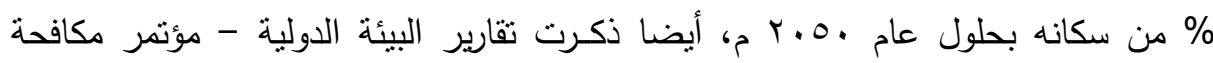

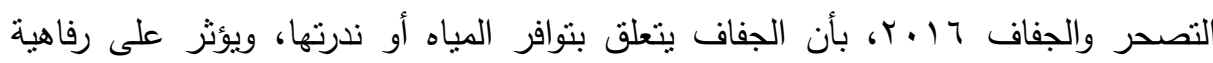

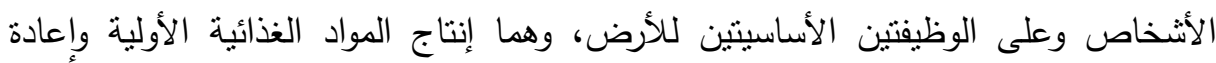
تدوير المغذيات، حيث تعني ندرة المياه، والفرق بين عرضها والطلب عليها، والطلب عليها

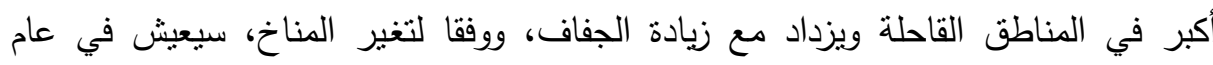

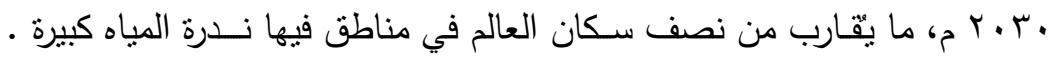

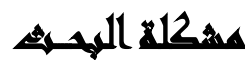

يُعتبر خطر التصحر محلـل اهتمام الكثيـر من المنظمات والهيئات الدولية وعلى

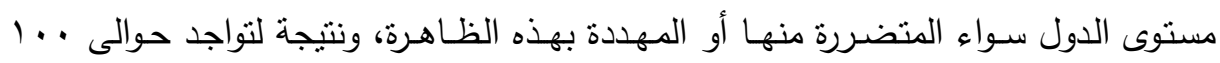
مليون نسمة أو أكثر من السكان يعيشـون على أرض مصـر ويُّتغلون هذه الرقعـة

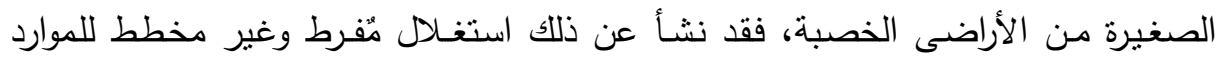
الطبيعية المتاحة، كما صـاحبه ضعف فى التقنيات، واستسهال فى تطبيق اللوائح والنظم

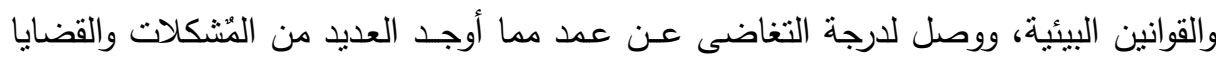

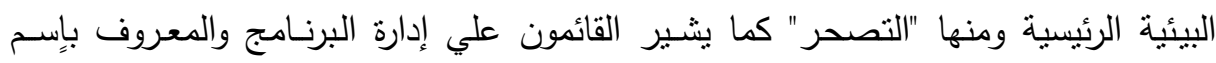

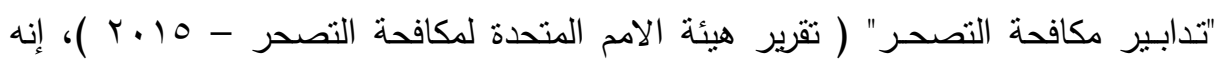

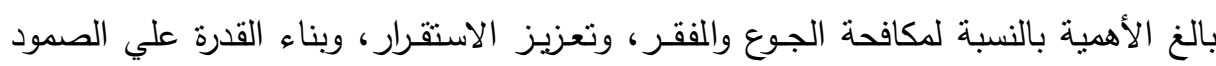

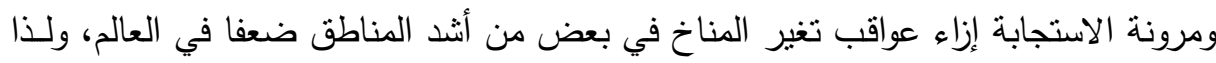

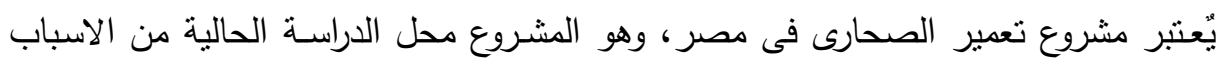


الاساسية لضعف وعدم زيـادة الانتـاج فى مصر ، حيث كان من المخطط لهذا المشروع أن

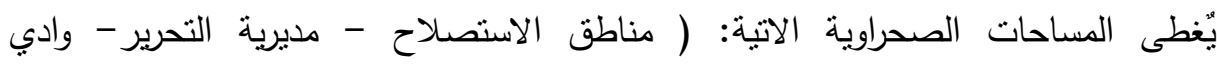
النطرون- الواحات البحرية - نتجير الطرق الصحراوية بمصر جميعها ) - مركز بحوث

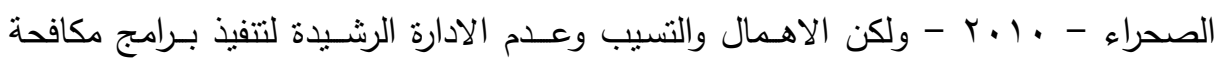

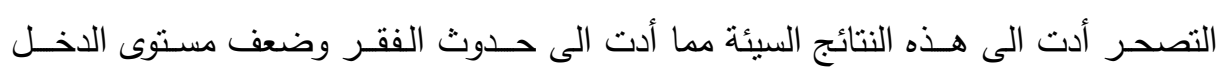
للدى الفرد ولـدى الدولة ككل - ومن ضمن هــــه المشـروعات التى تعهـل على مكافحة

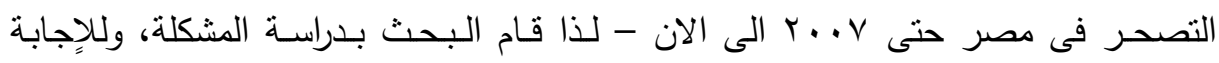

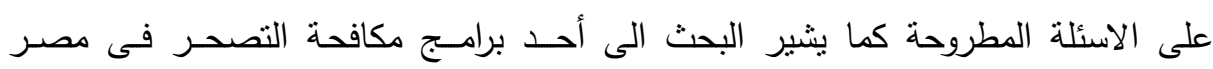

\begin{tabular}{|c|c|c|c|c|}
\hline موقع تنفيذ المشـروع & أهم أنشطة & يغطيها المشروع التى & الزمنية & المشاريع \\
\hline 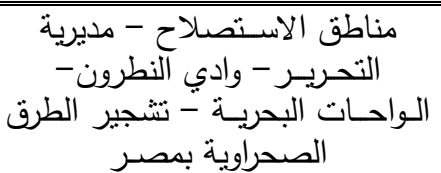 & وإستزبراع & - & - & تعمير \\
\hline
\end{tabular}

\section{أسرئلة الههمه}

أولاً: ما أوجها القصور لبرامج مشروعات مكافحة التصحر فى مصـر، وخاصة مشروعات

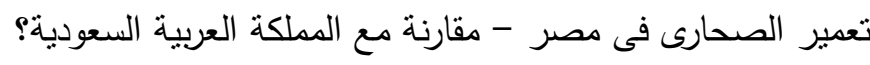

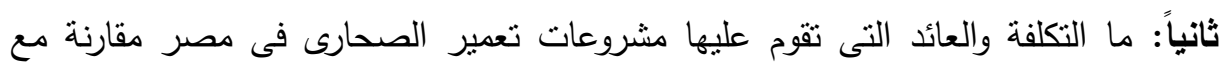

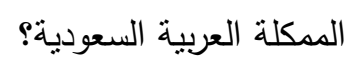
ثالثاً: ما المردود الاقتصادى والبيئى لمشروعات تعمير الصحارى فى مصر مقارنة مع

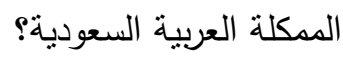
رابعاً: ما الشاكل والقضايا الاقتصادية والبيئية المتعلقة بمشروعات تعمير الصحارى فى مقيه

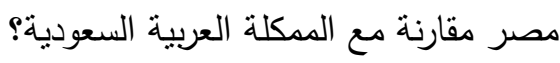
خامساً: ما الأسباب التى أدت الى ضعف العَ الإنتاج الزراعى فى مصر؟ 


\section{أهساهن المهيه}

\section{بهــدف البحث إلى تحقيـق النقـــاط التالية:}

- إككانية استخدام التكلفة والعائد فى تحليل برامج مشرعـات تعمير الصحارى بغـرض

$$
\text { زيادة الانتـاج الزراعى فى مصر . }
$$

- إمكانية التعرف على تحليل التكلفة والعائد، وكذلك المـردود الاقتصادى والبيئى

$$
\text { لمشروعـات تعمير الصحارى فى مصر . لمعرى }
$$

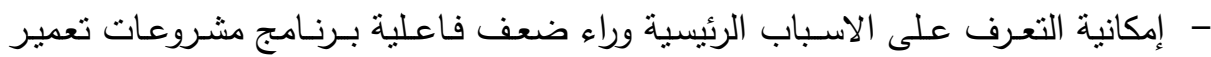
الصحارى فى مصر .

- إلقـاء الضوء على أوجـه القصور لبـرامج مشروعـات تعمير الصحارى فى مصر -

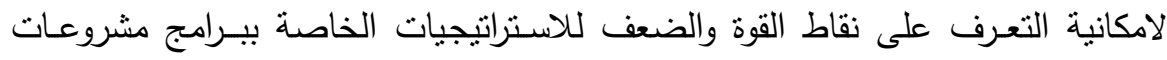
مكافحة التصحر فى مصر، وكيفية التعامل معها، للحد مـن والتغلب على ظـاهــرة التصحر، بغرض زيادة الانتاج الزراعى فى مصر - ومنع تأثيرها السلبى على الإِتصـاد

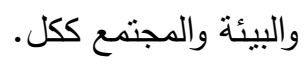

- وضع المقترحات والتوصيات وطرح الحلول العلمية المناسبة لزيـادة مشـروعات مكافحة التصحر فى مصر، وذللك من أجلـ صون ما تبقى من رصبد للموارد الطبيعية وزيادة

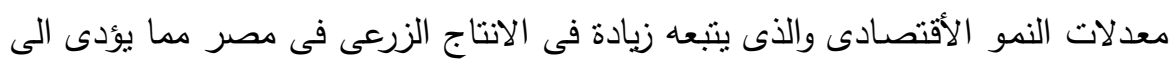

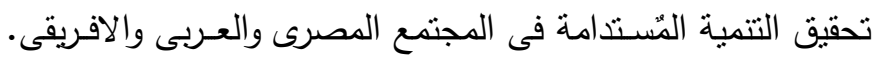

\section{الفمروغ المهثية}

الفـرض الوحيد: تـوجــ عـلاقة بين عـدم تـوفـر بيـانـات مشـروعات تعمير الصحسارى وضعف وعدم زيـادة الاتتـاج الـزراعسى فى مصر . 


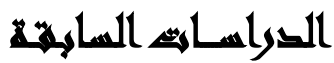

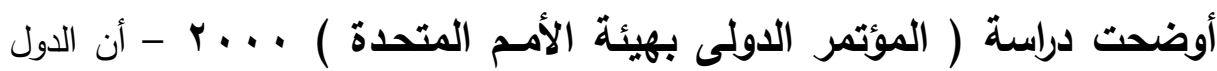

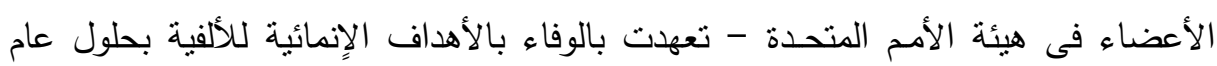

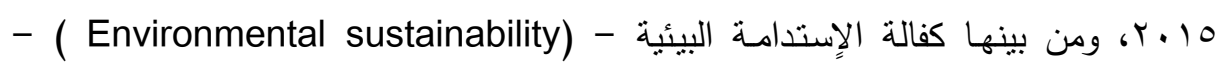

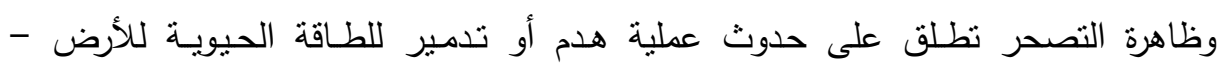

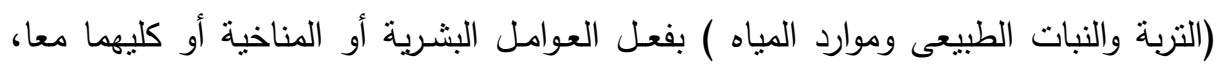

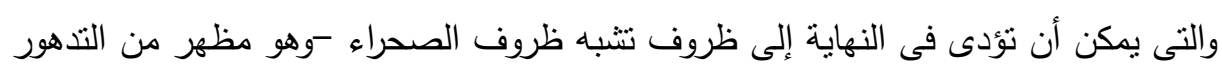

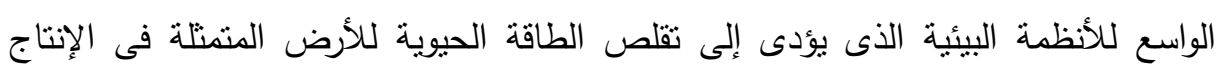

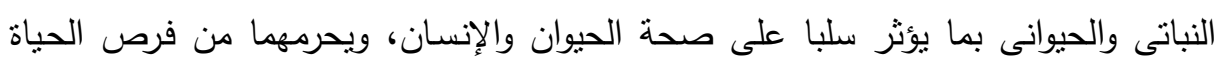

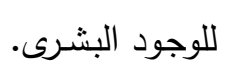

وأوضحت دراسة ( R. Hessel M. S. Reed N. Geeson C. J. Ritsema G.

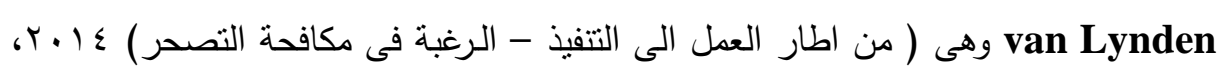

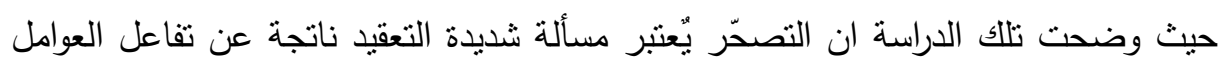

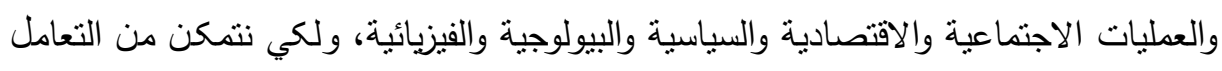

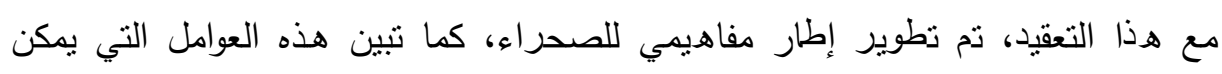

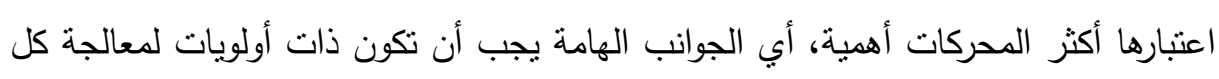

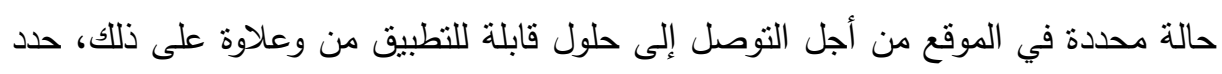

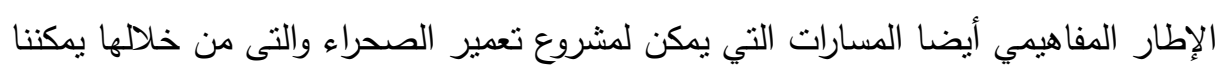

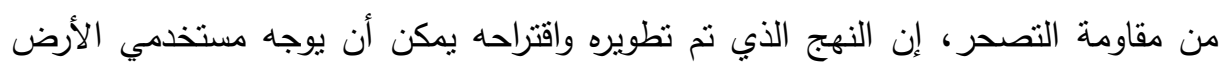

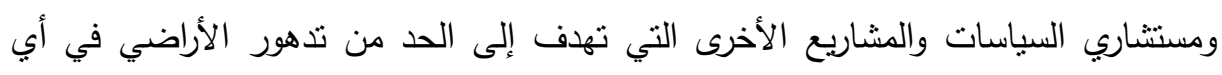
مكان في العالم. - مئن وتثير دراسة (Dasgupta Arunima, P S Dhinwaand A S Rajawat) 10 نتائج الدراسة أن التغيرات الإيجابية كبيرة في قيم NDVI للأراضي الزراعية - أيضا ضرورة

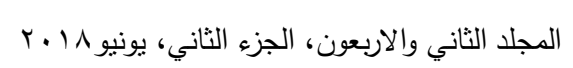


زيادة في المسطحات المائية السطحية - ضرورة زيادة مساحة الأراضي الزراعية نتيجة تعمير

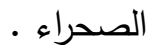
كما بينت دراسة (Alin Song, ( 2017 - Xiao Song Duanyang Xu) فى ( تقييم تأثير التصحر الذي يسيطر على المشاريع والسياسات في مقاطعة شنشي الثمالية، للصين

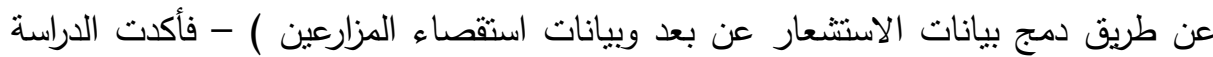
على ضرورة مكافحة التصحر ، وأظهرت النتائج أن الجمع بين هذين التقييميات التكميلية يمكن أن توفر معلومات شاملة لدعم صنع القرار، ووفقاً لبيانات الاستشعار عن بعد وصافي الإنتاج

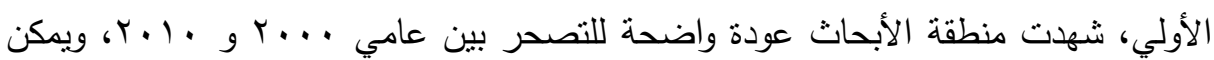

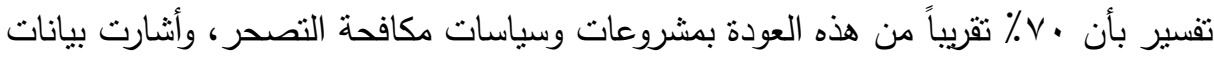

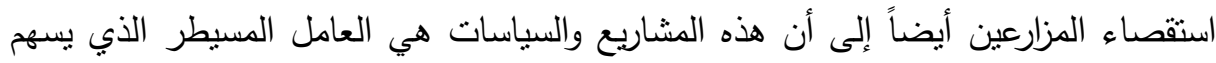
في عودة التصحر، وقد وافق ما يقرب من • ×\% من المزارعين المحققين على هذا الاستتناج ومع ذللك، كانت مستويات الإشراف والإعانة المنخفضة من القضايا التي حدت من تأثير السياسات، ولذلك ومن الضروري يجب أن تقوم الحكومة بتعزيز الإشراف ورفع مسنويات الدعم وتطوير أنظمة حماية البيئة لتتجيع المزيد من المزارعين على المشاركة في مكافحة التصحر، ولذا فإن هذا البحث، له أهمية بالغة في عمليتي استراتيجيات التخطيط، ووضع التهن دراسـات الجدوى الاقتصادية والبيئية لمشروعات تعمير الصحارى فى مصر، حيث بمثل

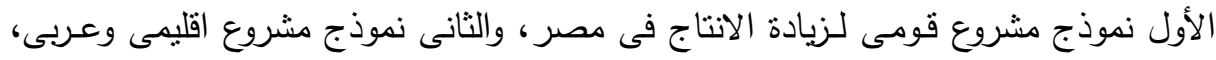

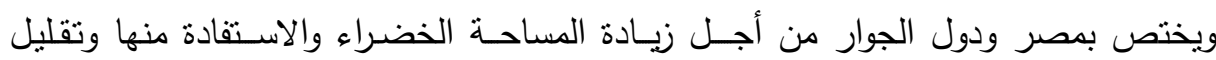

$$
\text { الانبعاثات لغـاز ثنانى اكسيد الكربون. }
$$

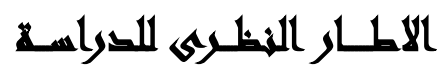

تعد الدراسة الحالية بمثابة التقييم الاقتصادى والبيئى لبرامج مشروعات تعمير الصحارى

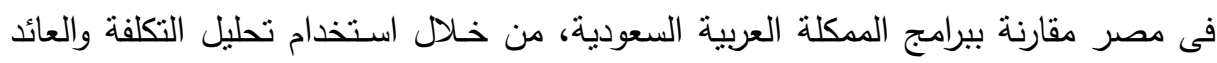
لهذه البرامج، حيث أن دراسة الجدوى الاقتصادية هي تُعتبر أداة علمية تستخدم لترشيد منيد 
القرارات الاستثمارية الجديدة أو لتقييم قرارات سبق اتخاذها أو القيام بمفاضلة بين البدائل

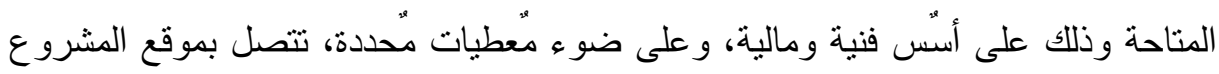

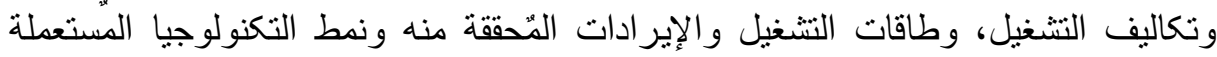
والايدى العاملة الموظفة "، ومن هذا التعريف يتضح وأن دراسة الجدوى الاقتصادية تتصف

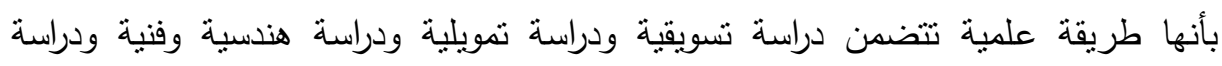
قانونية ودراسة مالية تتصف بالابتعاد عن العشوائية في القرارات، أما دراسة الجدوى البيئية

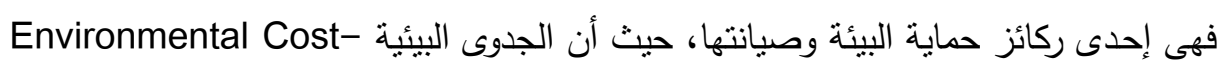

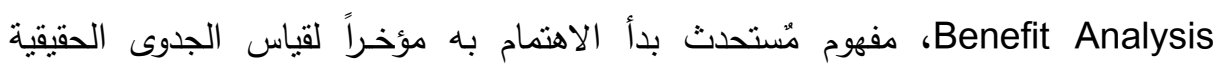
للمشروعات الإنمائية التي كانت تعتىد فقط حتى وقت قريب على دراسات الجدوى الاقتصادية Cost-Benefit Analysis Economic للمشروعات المُّترحة في خطط التتمية، دون مراعاة لظروف البيئة وإمكاناتها والتأثيرات

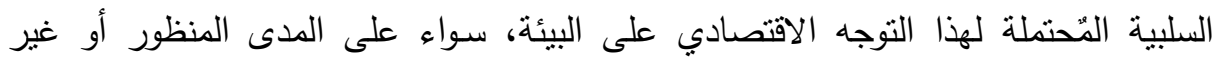

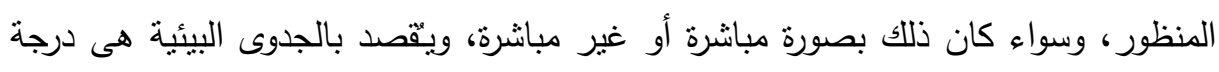
الحماية والصيانة التي تتحقق للبيئة من خلال مراعاة القدرة أو الطاقة القصوى لإمكانات

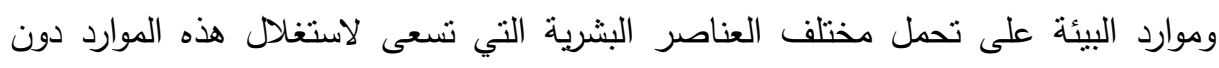

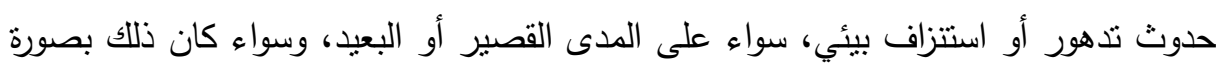

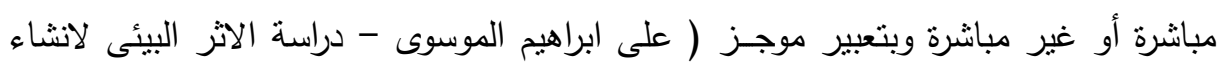

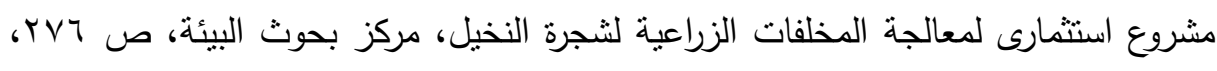

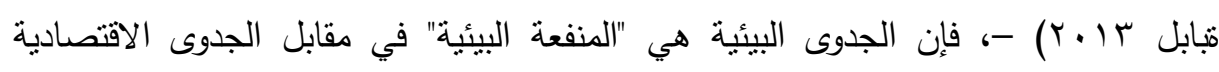

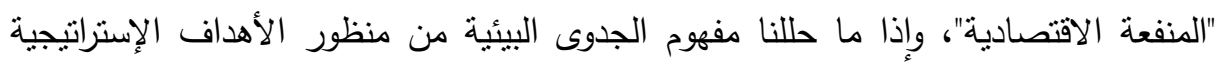

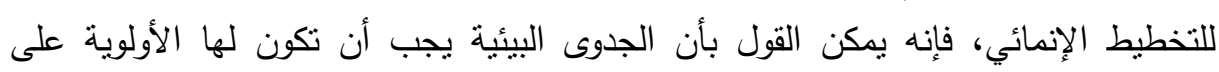
الجدوى الاقتصادية في أي تخطيط نتموي ناجح، يستهدف تحقيق التتمية المُّندامة أو القابلة

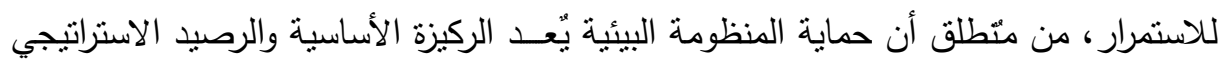

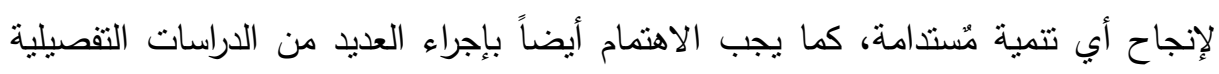

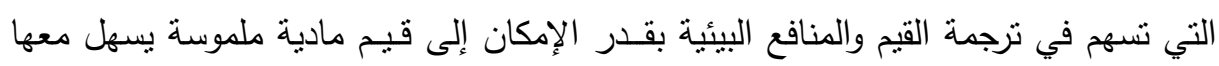

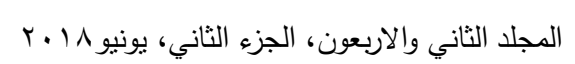


قياس الجدوى البيئية للمشروعات، واعتبار نتائج هذه الدراسات بمثابة نماذج للتقييم في البيئات

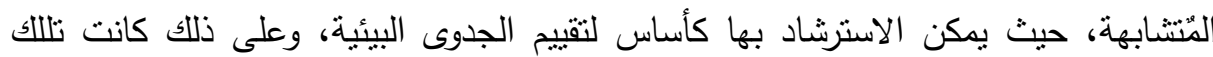

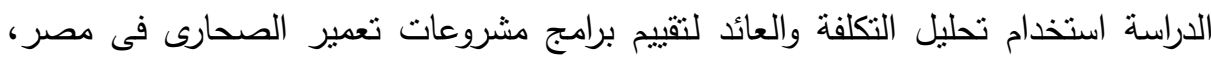
وعليه يمكننا نوضيح مفهوم تحليل التكلفة والعائد وتعمير الصحارى على النحو النالى :أولاً- تحليل التكلةة والعائد / ) (Cost-Benefit Analysis) (CBA )، يُطلق عليه في بعض الأحيان تحليل الفائدة والتكلفة (BCA )، عبارة عن عملية منهجية يمكن من خلالها حساب فوائد وتكاليف مشروع أو قرار أو سياسة حكومية ("المشروع") ما والمقارنة بينها، وهناك غرضان لتحليل التكلفة والعائد الاتى : ( Ferrara, A. Cost-Benefit Analysis of Multi-Level Government: The Case of EU Cohesion Policy and US Federal Investment Policies, London and New York: Routledge. 2010 )

$$
\text { - تحديد ما إذا كان الاستثمار / القرار الذي تم اتخاذه سليمًا ( التبرير / الجدوى). }
$$

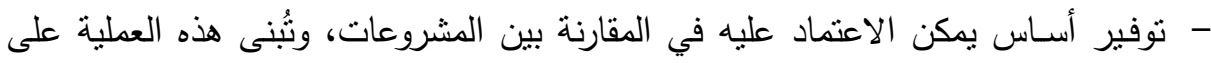
أساس المقارنة بين التكلفة الإجمالية المتوقعة لكل خيار في مقابل الفوائد الإجمالية

$$
\text { المنوقعة، لمعرفة ما إذا كانت الفوائد تفوق التكاليف، وبأي كمية. }
$$

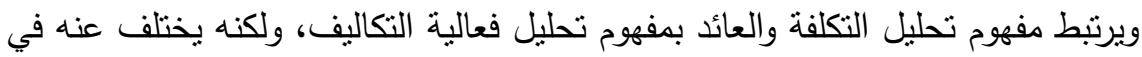
نفس الوقت في مصطلح تحليل التكلفة والعائد، ويتم التعبير عن الفوائد والتكاليف بمصطلحات نقدية، ويتم ضبطها على القيمة الوقتية للنقود، وبالتالي يتم التعبير عن كافة تدفقات الفوائد، وكذللك تدفقات تكاليف المشروع بمرور الوقت، والتي تتجه إلى الحدوث عند نقاط مختلفة في وقتها المناسب، على أساس مُشترك من حيث "صافي القيمة الحالية " الخاصة بها، وتُعتبر

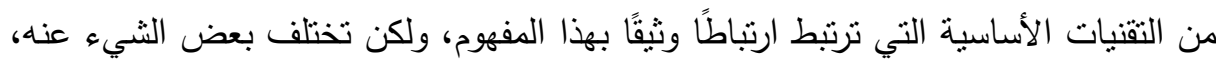

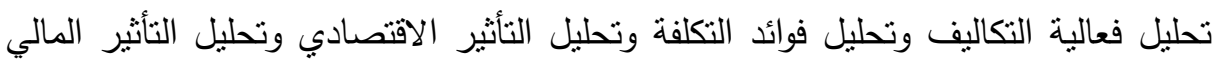
وتحليل العائد الاجتماعي على الاستثمار ( SROI )، وقد تم تكييف منهجية SROI. Folland, Sherman, Allen C. Goodman and Miron Stano. The Economics of Heath and Health Care. Fifth ed. Pearson Prentice Hall: New Jersey, 2007. pg 83, 84 .

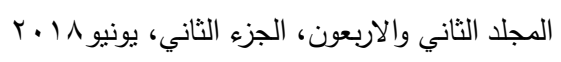


بشكل إضافي لاستخدامها في تخطيط وترتيب أولويات التكيّف والتأقلم مع التغيّرات التتموية، على سبيل المثال، يعتمد إطار المشاركة الاجتماعية على الاستثمار (PSROI) على ولى

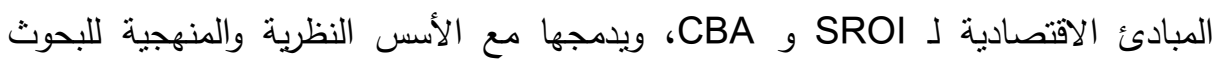

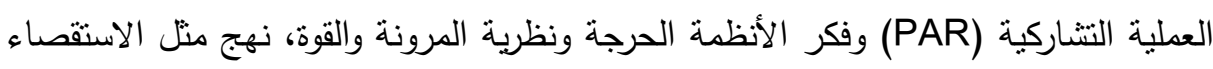

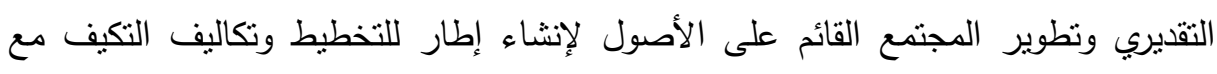
تغير المناخ في النظم الزراعية، وبالتالي، تمثل PSROI التقارب بين مسارين نظريين هما:

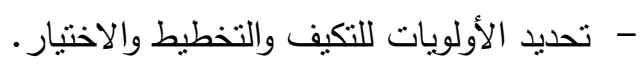
- -

والاختلاف الرئيسي، إذن، بين SROI و PSROI هو أنه على الرغم من أن PROI

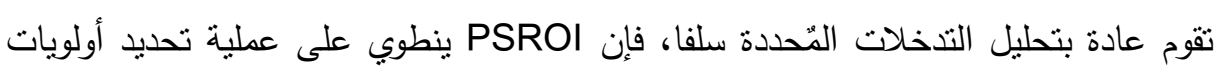

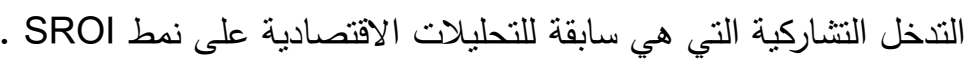
المصروف expenses: هو التكلفة المنتفذة خلال الفترة في خلق ايرادات الفترة او هو تكلفة مرتبطة بالحصول علي الايرادات خلال فترة محاسبية معينة . Quigley, John and Lesley Walls. "Cost-Benefit Modelling for Reliability Growth." The Journal of the Operational Research Society 54, no. 12 (2003): 1234-41

النققة expenditure : التضحيات الاقتصادية الصريحة او التعاقدية التي تتحملها المنشاة، -اوتعرف بانها المعاملات النقدية فقط سواء كانت تللك المعاملات مرتبطة بالحصول علي منافع او خدمات فورية او كانت مرنبطة بالحصول علي منافع وخدمات مستقبلية. التكلفة cost: هي كافة التضحيات الاقتصادية الاختيارية (صريحة أو تعاقدية، ضمنية أو

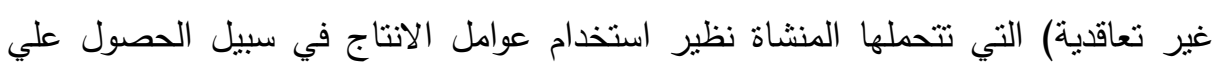
منفعة حاضرة او مستقبلية. الفرق بين النققة والتكلفة والمصروف والخسارة ولزيادة المنفعة (العائد):

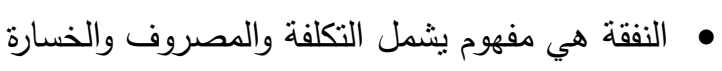

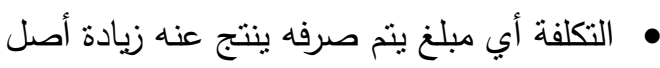


• المصروف أي مبلغ يتم صرفه للحصول على إيراد • الخسارة هى تعبر عن أي مبلغ يتم صرفه و لا ينتج عنه زيادة في أصل أو حصول على على ائى

التكلفة الغارقة: هو مصطلح أو أسلوب يكثز استخدامه في المحاسبة الإدارية ودراسات الجدوى ولا يستخدم في المحاسبة المالية ـويشير هذا المصطلح إلى تجنب إدراج تكلفة أصل

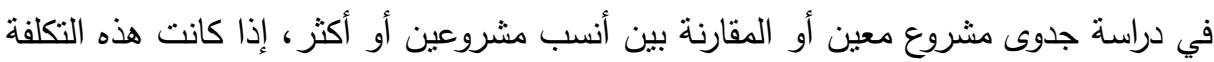
سنكون موجودة عند إختيار هذا المشروع أو عدم اختباره. العـائـــ المنفعة: يعرف علم التمويل معدل العائد (Rate of Return) (ROR) (R) ويطلق عليه أيضًا اسم عائد الاستثمار (ROI)، معدل الربح أو العائد فقط، بنسبة الأموال في ربح أو خسارة (سواء أكانت محققة أم غير محققة ) Kosub, Jeffry, "Transitioning to a Greener Fleet: A Cost-Benefit Analysis of a Vehicle Fleet Program at the Texas General Land Office in Austin, Texas . (2010).

في استثمار ما، بالنسبة إلى الأموال التي نم استثمارها، ومن الممكن الإثارة إلى الأموال

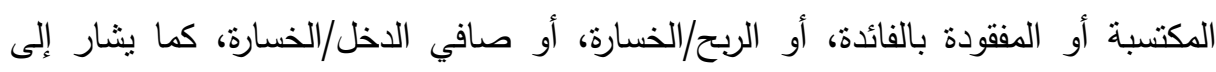

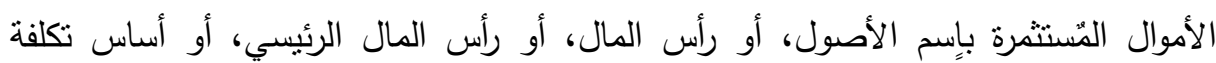
الاستثمار ، وعادة ما يتم التعبير عن عائد الاستثمار بالنسبة المئوية . تعمير الصحارى: تتوزع الصَّحراء على شكل أجزاءٍ في جميع أنحاء العالم لكثُوِّن مساحة

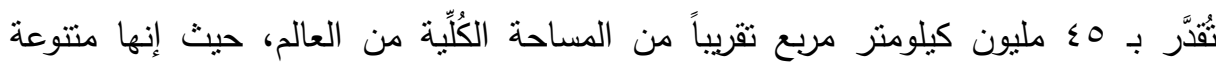
المناخ، فمنها الصحراء الباردة كالتي في القطب الثمالي والقطب الجنوبي، والصَّحراء الحارَّة كالتي في الوسط من الكرة الأرضية أو القريبة من الوسط كالصنّحراء الإقريقية والأسترالية،

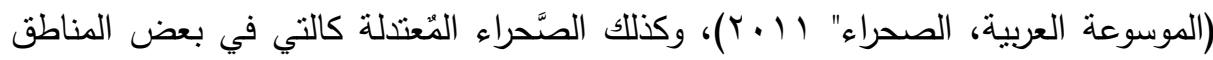

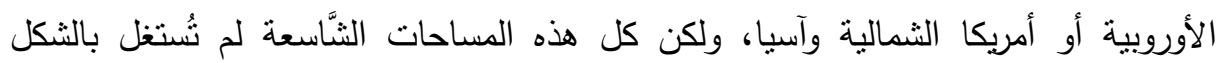

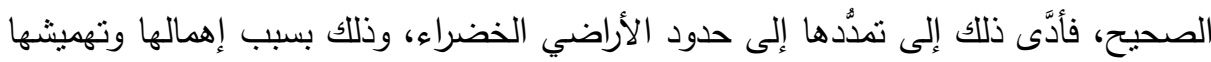

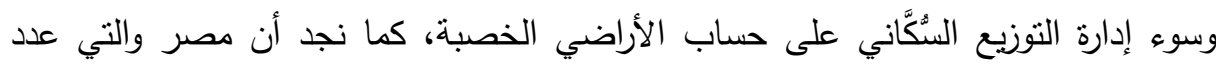
378

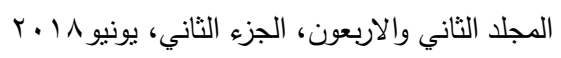


سُكَّانها يُقََّّر بمائة مليوناً وأكثر ، موزَّعين على مساحةٍ نسبتها أربعة في المائة من المساحة

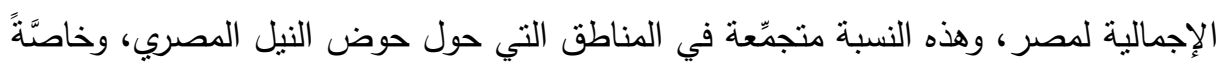

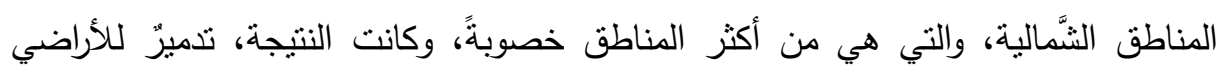

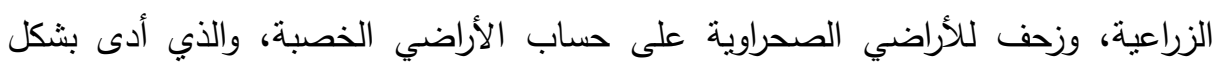

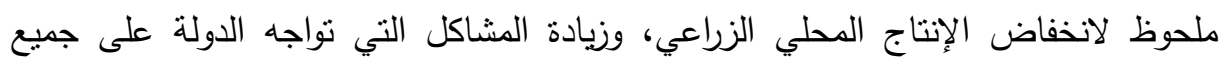
الأصعدة الاقتصادية، والصحية، والسياسية، والبيئية والاجتماعية، ولذلك يمكننا رؤية النتائج

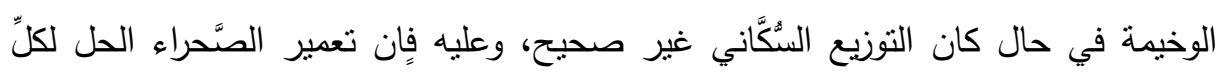

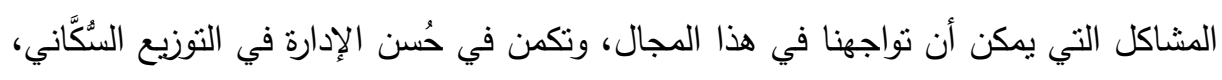

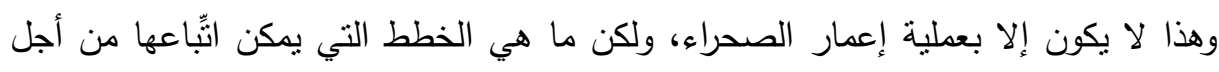

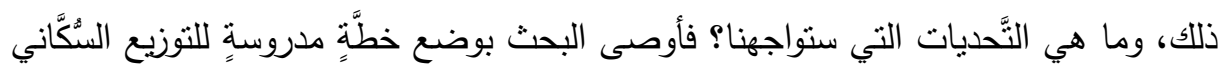
ويكون ذلك بشكل صحيح على جميع أراضي الدولة، وهذا بمكن أن يكون بنقل المشاريع

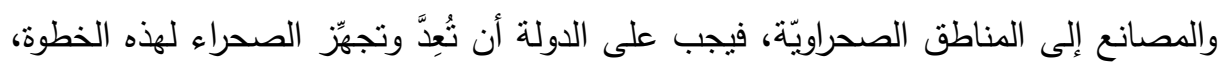

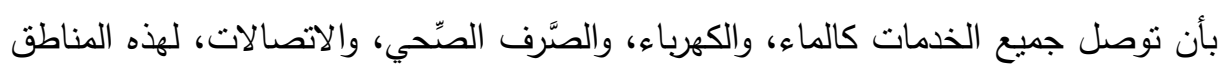

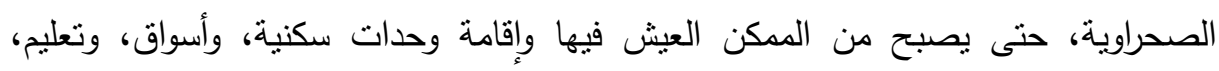

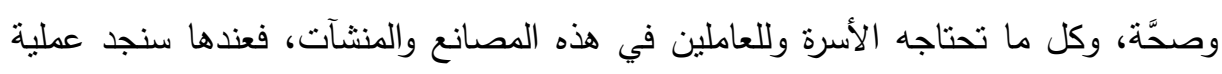

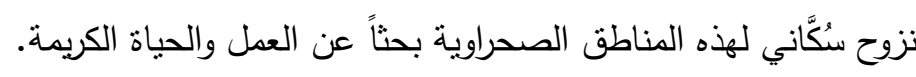
تعمير الصحراء بيئيًَا: تعتبر هى عملية استصلاح للأراضي الصحراوية، بأساليب علمية

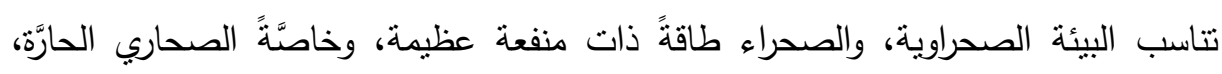

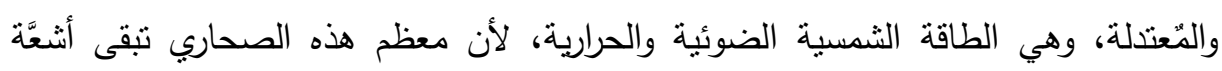

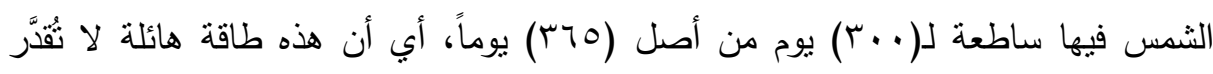

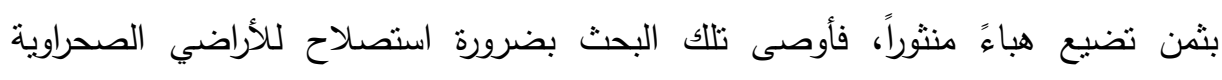

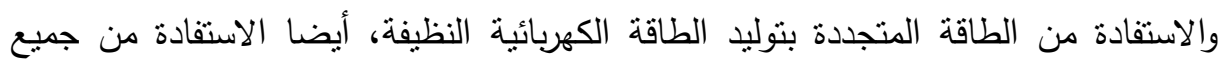
النظم البيئية الممكنة والمنواجدة بالصحراء وصيانتها وحميايتها اقتصاديا وبيئيا . 


\section{لإجراءايش المهيه}

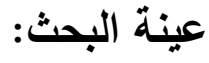

وصف عينة البحث: اختيرت منطقة الدراسة بما يتوافق مع أهـداف البحث، حيث كانت عدد

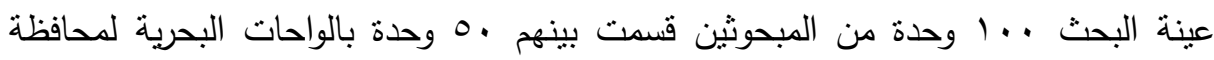

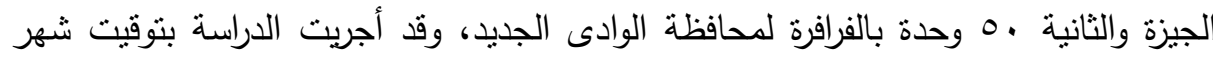
اكتوبر ونوفمبر وديسمبر لعام Y. VV، مع المبحوثين المزارعين بمنطقى عينة الدراسة

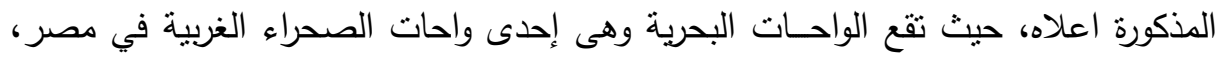

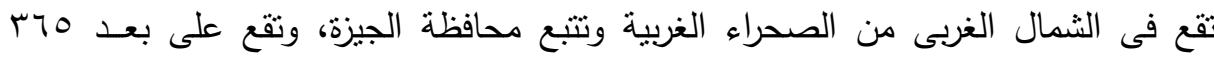

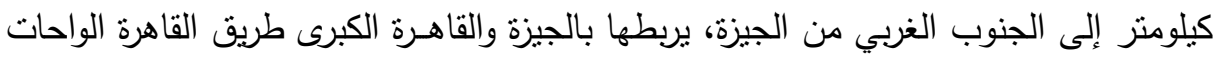

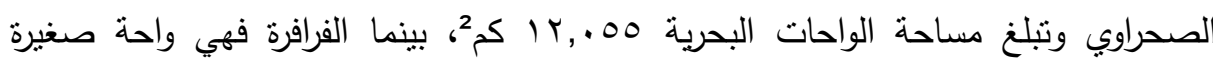

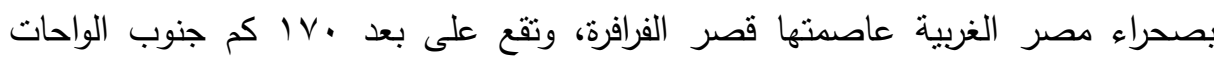

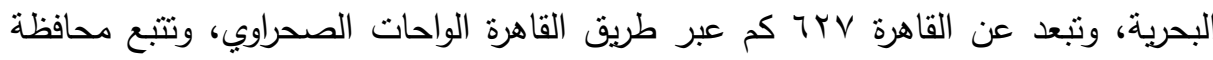
الواداى الجديد، وقد ذاعت شهرتها في العالم ووضعت تحت الأضواء سياحيا وعلميا بسبب موقعها وتاريخها ونوعية صخورها وأثنكالها وجوها المشمس الدافئ وجبال الكريسنال بمنطقة

أداوات البحث: تم تصميم إِتنمارات الإستنيان ونم تجميعها من الواحات والفرافرة بمحافظتى

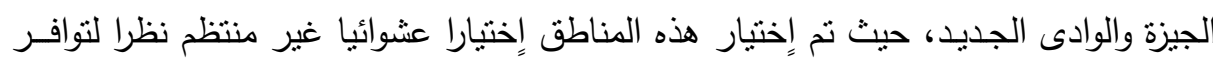

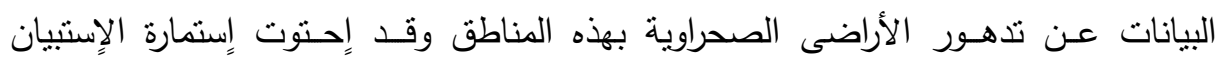

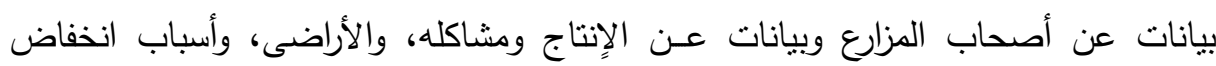

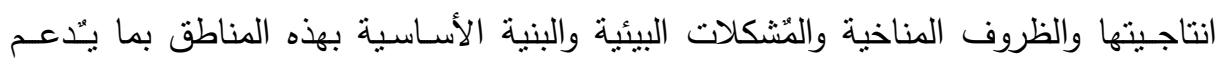

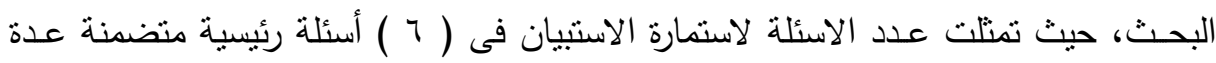

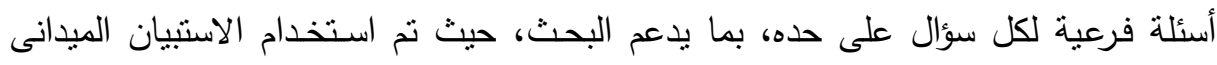

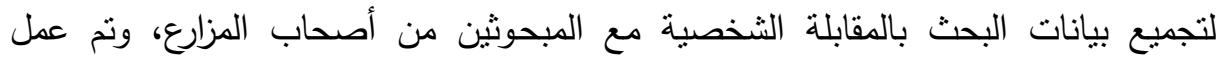

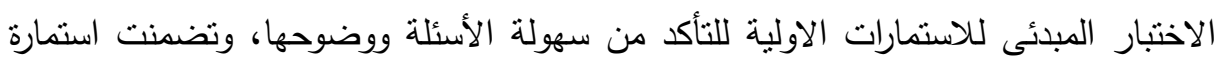


الاستبيان المطلوبة لتحقيق أهداف الدراسة وقد تضمن اختيار العينة نوعين من المفردات

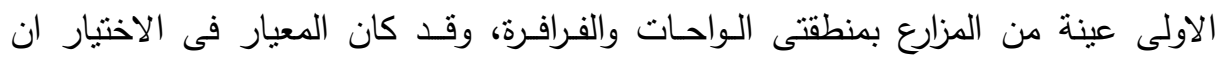
تكون مزارع ذات نشاط زراعى حالى وسابق وكان الاختيار عشوائى غير منتظم على ان تكون

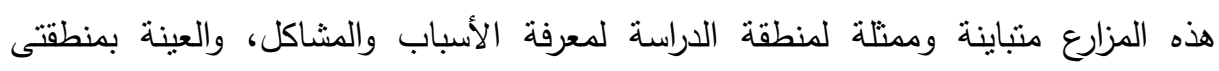
الواحات البحرية والفرافرة بمحافظتى الجيزة والوادى الجديد. صدق وثبات الاستبيان: قد نم قياس الثبات والصدق لاسئلة الاستبيان الخاصة بالبحث

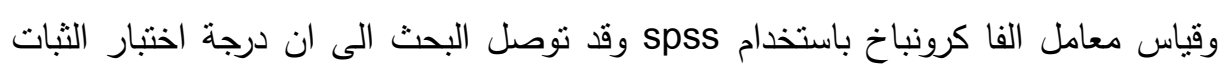

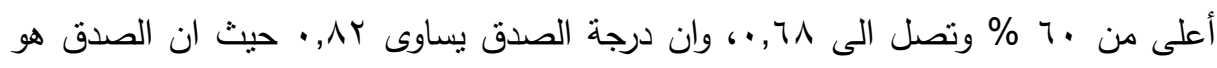

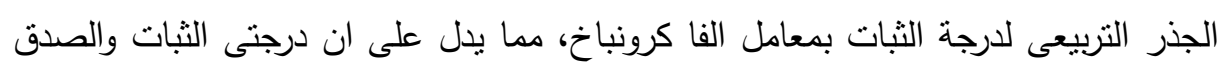
عالية بالحكم على ثبات الاستبيان الخاصة بالبحث. لتربه

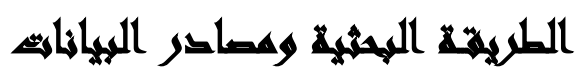

تم الاعتمـاد على طريقتى التحليل الإحصائى الوصفى والكمى والتحليلى وإعتمد البحث على بيانات ميدانية كما نم الحصول عليها من عينة الدراسة الواقعة بمحافظتى الجيزة

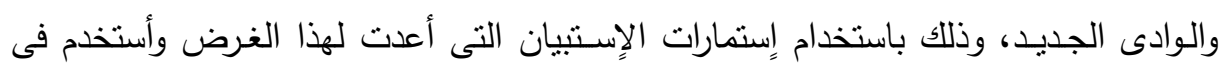
تحقيق أهداف هذا البحث نوعان من البيانات هما البيانات الثانوية والبيانات الأولية، حيث البيث

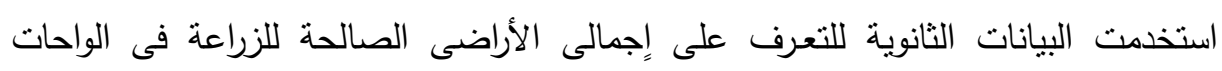

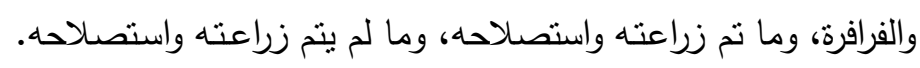

\section{السواسمة الميشانية}

موقع الاراســة: تمت الدراسة الميدانية بمدينتى الواحات والفرافرة بمحافظتى الجيزة والوادى

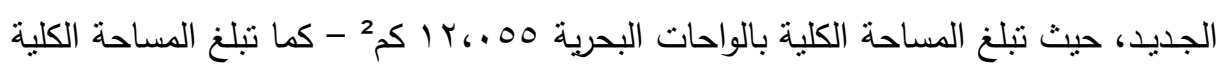

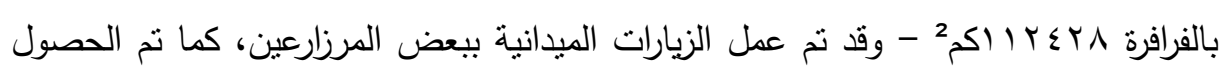

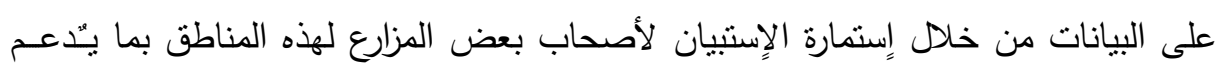
البحـث. 


\section{النمخائم}

الإجابة على السؤال الأول واليرابع معاً يتلخص فى تحديد الأهمية النسبية على النحو التالى:

أولاً الأهمية النسبية: لأسباب عدم تعمبر الصحارى بعينة الدراسة تضمن الإستبيان

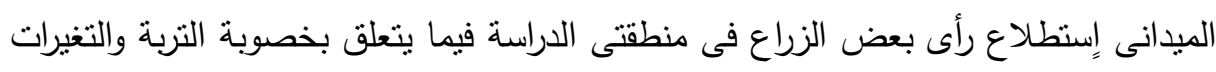

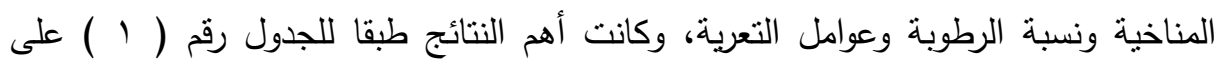
النحو التالى: 1 خصوية التربة: تبين من أراء عينة البحث بالفرافرة لمحافظة الوادى الجديد أن نحو ץ,بس

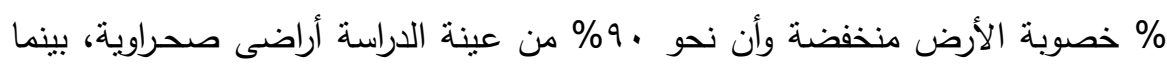
عبنة الدراسة فى الواحات البحرية لمحافظة الجيزة، كانت خصوبة التربة منخفضة بنحو

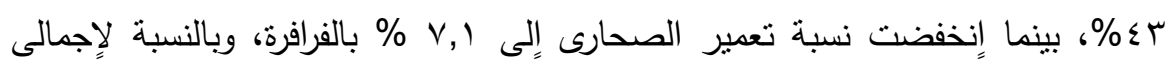

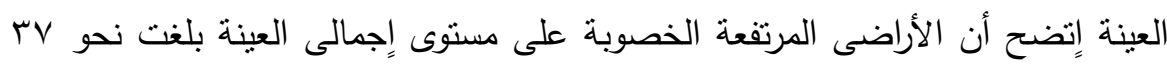

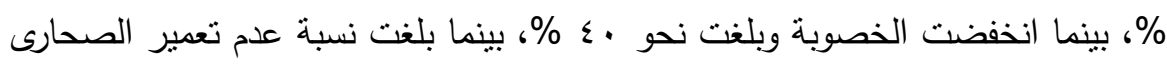

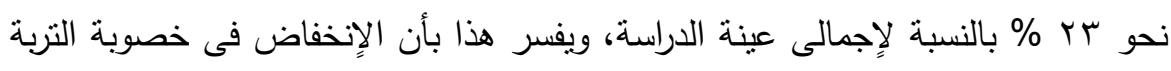

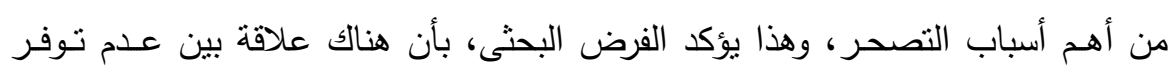

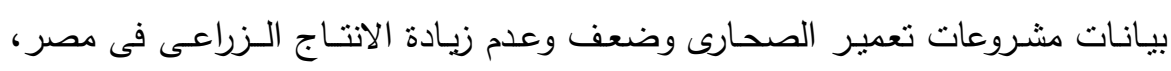

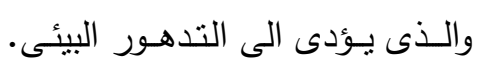

r- التغيرات المناخية: إتضح أن أراء عينة الدراسة تمثلت فى أن التغيرات المناخية متمنلة

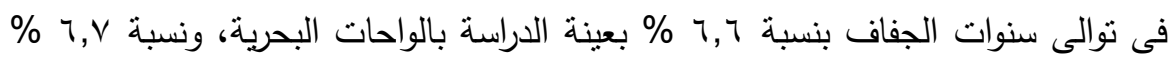

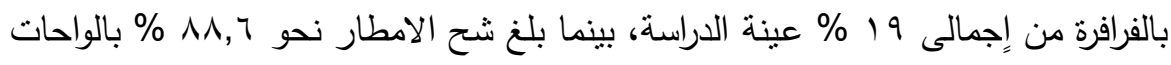

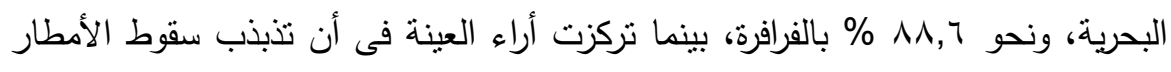

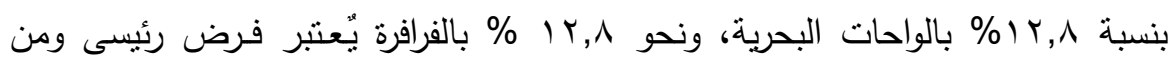

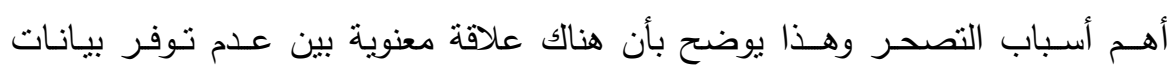

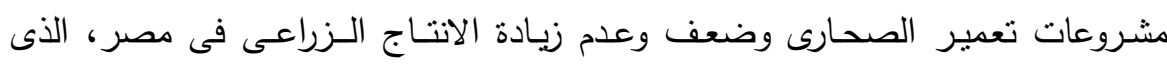
يؤدى الى التدهـور البيئى. تعمئ. 
r- نسبة الرطوية: تبين من أراء عينة الدراسة بالوحات البحرية أن نسبة الرطوبة كانت

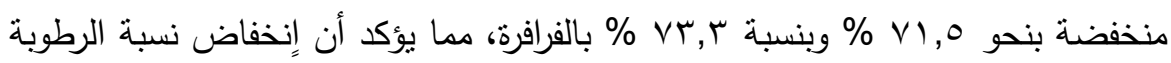

$$
\text { ينوافق مع صحة الفرض البحنى. }
$$

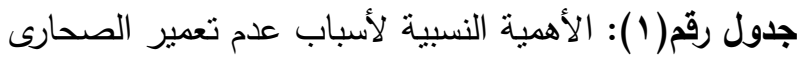

\begin{tabular}{|c|c|c|c|c|}
\hline \multicolumn{2}{|c|}{ الفرافزة } & \multicolumn{2}{|c|}{ الواحات } & \multirow{2}{*}{ المحافظات } \\
\hline$\%$ & عدد & $\%$ & عدد & \\
\hline \multicolumn{5}{|c|}{ خصوبة التربة } \\
\hline 0. & ro & $7, V$ & $r$ & مرتفعة \\
\hline$\sum r, q$ & $r$. & $r \mu, r$ & 1. & منخفضة \\
\hline $7, V$ & IV & 7,7 & $r$ & توالى سنوات الجفاف \\
\hline$\wedge \wedge, 7$ & $\pi$ & $\wedge \wedge, \uparrow$ & $r$. & شح الأمطار \\
\hline$I_{1, \Lambda}$ & Tr & $1 Y, \Lambda$ & $\Lambda$ & تذبذب سقوط الأمطار \\
\hline \multicolumn{5}{|c|}{ نسبة الرطوبة } \\
\hline $17, V$ & $\Lambda$ & $11, \varepsilon$ & 0 & مرتفعة \\
\hline $\mid V, I$ & IT & $1 \cdot, \cdot$ & $r$ & متوسطة \\
\hline$V \Psi, r$ & 0. & $v 1,0$ & $T r$ & منخفضة \\
\hline \multicolumn{5}{|c|}{ مصدات الرياح } \\
\hline$\vee \wedge, 7$ & 00 & $r\rceil, V$ & $\Lambda$ & توجد \\
\hline$V r, r$ & 10 & $Y_{\top, \varepsilon}$ & Yr & لا توجد \\
\hline \multicolumn{5}{|c|}{ عوامل التعرية } \\
\hline$r \mu, r$ & $1 \pi$ & 11,7 & $\mathrm{~V}$ & رياح شديدة \\
\hline $7, \cdot$ & $\mathrm{v}$ & $7, \cdot$ & $r$ & كثبان رملية \\
\hline$\Lambda, 7$ & 0. & $10, r$ & $r$. & جفاف أبار \\
\hline
\end{tabular}

؟ - عوامل التعرية: تمثلت أراء عينة الدراسة أنه من أسباب عدم تعمير الصحارى - بعينة

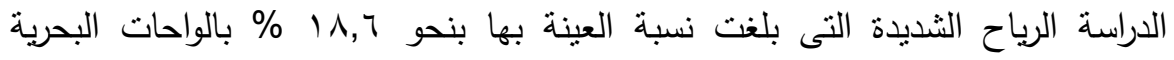

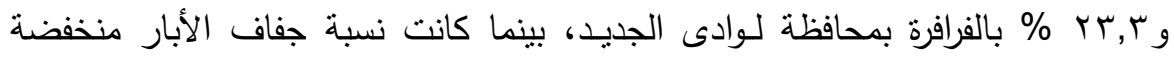

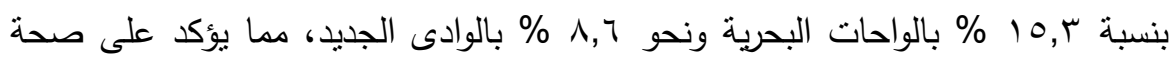

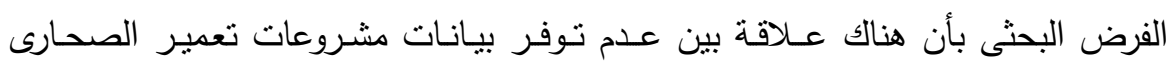

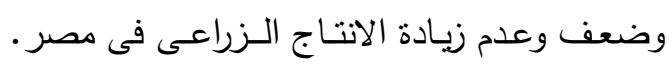




\section{ثانيا الأهمية النسبية لنوع المياه ووتكاليف الرى وطرق الرى ونوع الرى وخدمة الأراضى ونوع التربة ومشاكل الإنتاج:}

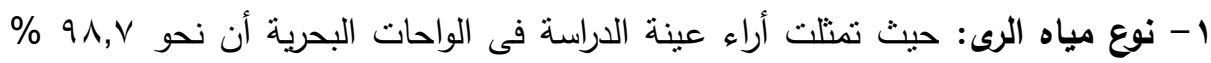

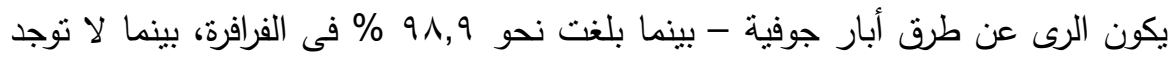
أراضى نروى بمياه النبل فى أو عينة الدراسة بالواحات البحرية والفرافرة، أما مياه الأمطار فلم يتم إستخدامها فى عمليات الرى بعينة الدراسة بالواحات البحرية، بينما بالفرافرة لم يتم

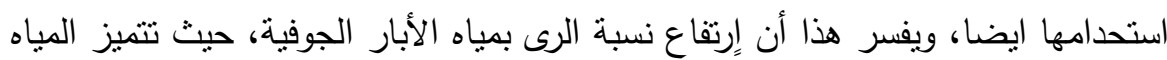

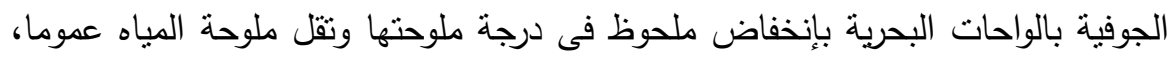

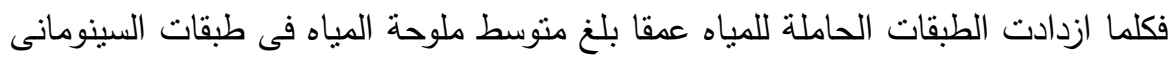
الأعلى حوالى

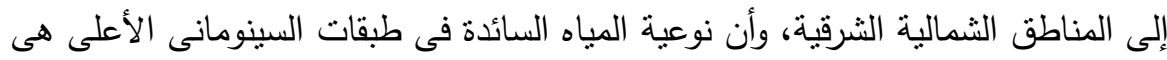
نوعية المياه البيكربوناتية الكلوريدية الصودية المغنيزية، بينما نوعية المياه الكيميائية

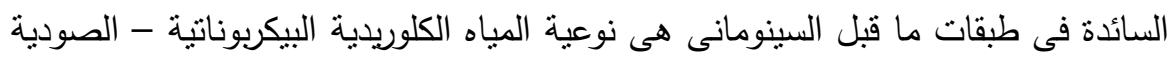

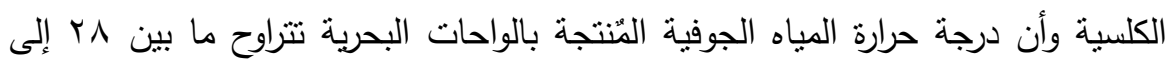

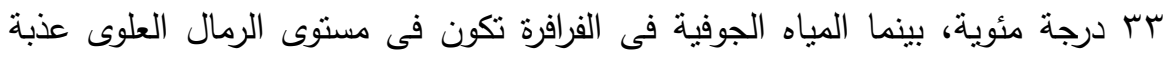
وملوحة المياه فى حدود مrكمجم/لتر، ومن الناحية الكيميائية فإن النوع السائد للمياه

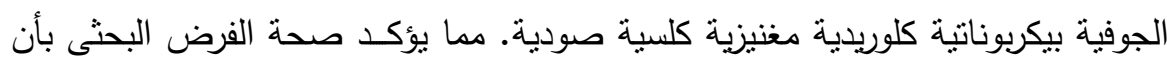

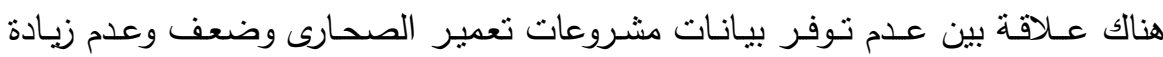

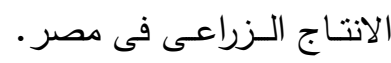

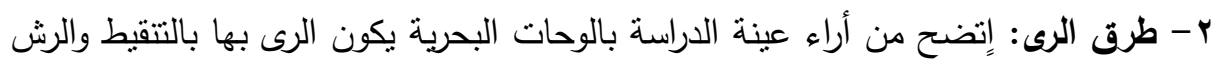

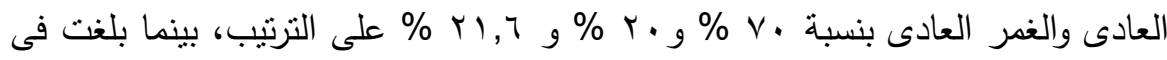

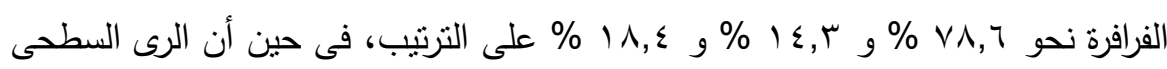
المطور والرى الارتوازى لم يتم إِتخدامهما فى أراضى الواحات والفرافرة بعينة الدراسة. 
r- تكاليف الرى: تنثلت أراء عينة الدراسة فى أنه من أسباب التصحر إرتفاع أجر الألات

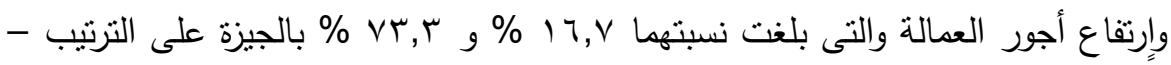

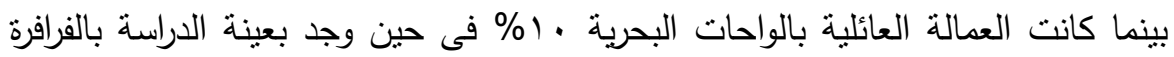

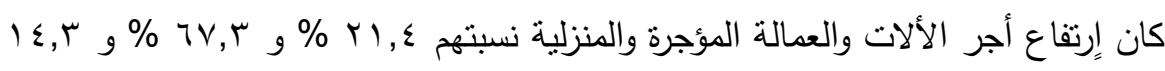
\% على الترتيب، مما يؤكد أن إرتفاع نسبة العمالة المؤجرة من أهم أسباب تدهور

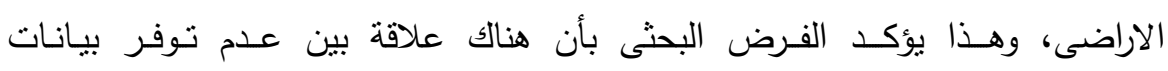

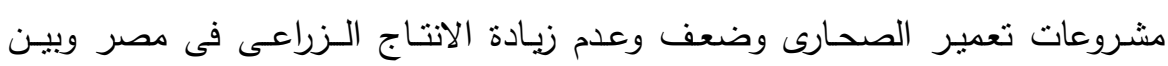

$$
\text { المُتنغـيرات الإقتصنادية. }
$$

جدول رقم(ب): الأهمية النسبية لنوع المياهو و وتكالف الرى و طرق الرى ونوع الرى الرى

\begin{tabular}{|c|c|c|c|c|}
\hline \multicolumn{2}{|c|}{ الَفرافَرَة } & \multicolumn{2}{|c|}{ الواحات } & \multirow{2}{*}{ المتغيرات } \\
\hline$\%$ & عدد & $\%$ & عدد & \\
\hline- & - & - & - & ارتوازي \\
\hline- & - & $\overline{-}$ & $\overline{-}$ & مياه النيل \\
\hline- & - & $r, 1$ & $T$ & مياه الأمطار \\
\hline$\vee \wedge, 7$ & 00 & $V \cdot$ & YI & تتقيط \\
\hline $1 \leqslant, r$ & 1. & r. & 7 & رش م \\
\hline - & $\cdot$ & . & . & محوري \\
\hline • & . & . & . & سطحي مطور \\
\hline $1 \wedge, \varepsilon$ & $r$. & Y I,T & $r$. & غمر عادى \\
\hline YI, & 10 & $17, \mathrm{~V}$ & 0 & ارتفاع اجر آلات \\
\hline$T \xi, \Gamma$ & $\leqslant 0$ & $V \mu, \mu$ & Tr & عمالة مؤجرة مرتفعة \\
\hline $1 \varepsilon, \Gamma$ & 1. & 1. & $\mu$ & عمالة منزلية \\
\hline$\varepsilon, \Gamma$ & $\mu$ & $7, V$ & $\bar{r}$ & صخرية \\
\hline$\overline{\Lambda \Lambda, T}$ & $7 r$ & $\overline{v \mu, \mu}$ & Tr & رملية \\
\hline $1, \varepsilon$ & 1 & $17, V$ & 0 & جيرية \\
\hline$\cdot$ & . & . & . & ملحية \\
\hline $1, \varepsilon$ & 1 & 0.0 & - & طينية \\
\hline$\overline{V \wedge, 7}$ & 00 & $\overline{V T, r}$ & $\overline{T Y}$ & مرتفعة \\
\hline $1 \leqslant, \Gamma$ & 1. & $17, V$ & 0 & متوسطة \\
\hline $\mathrm{V}, 1$ & 0 & 1. & $r$ & منخفضة \\
\hline$\overline{Y \Lambda, T}$ & $r$. & $T \mu, \mu$ & $\varepsilon$ & توافر المستلزمات \\
\hline$r 0, v$ & ro & $\overline{T \mu, r}$ & $\xi$ & عدم توافر المستلزمات \\
\hline$v, 1$ & 0 & $1 \mu, \mu$ & $\varepsilon$ & عدم توافر خدمات الميكنة \\
\hline$T \varepsilon, \Gamma$ & 1. & $\mu \mu, \mu$ & 1. & انخفاض الانتاج الزراعي \\
\hline
\end{tabular}

المصدر: جمعت وحسبت من استمارة الاستيان الميدانية.

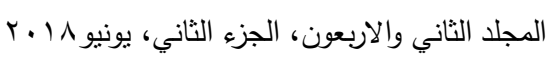


ع - نوع التربة: نبين مـن أراء عينة الدراسة فى نوع التربة الزراعية، حيث أن الأراضى

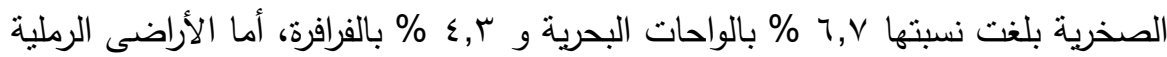

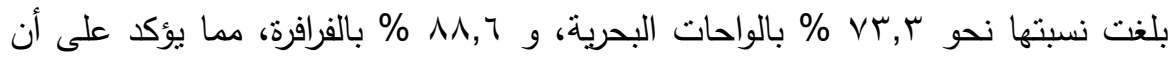

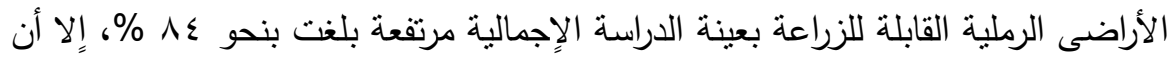

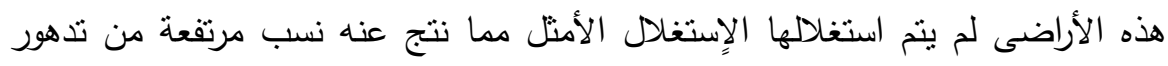

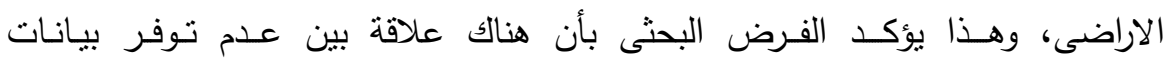

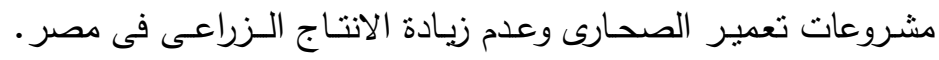

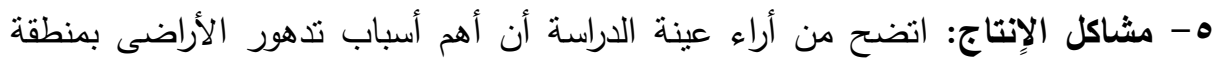

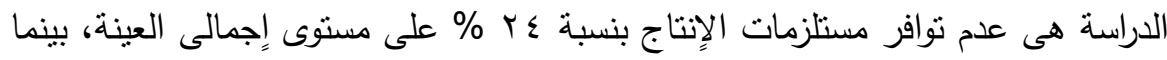

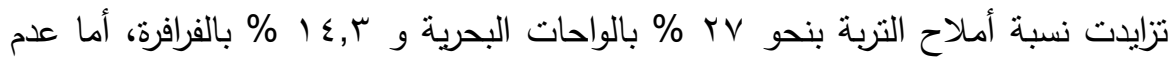

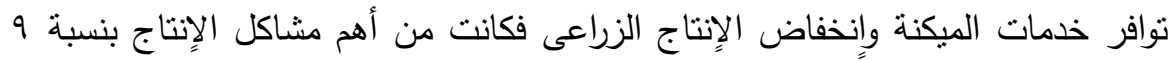

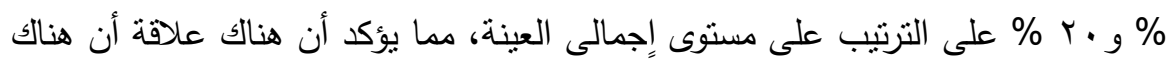
علاقة بين عدم توفر بيانات مشروعات تعمير الصحارى وعدم زيادة الانتاج

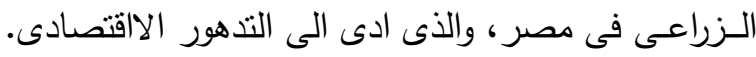

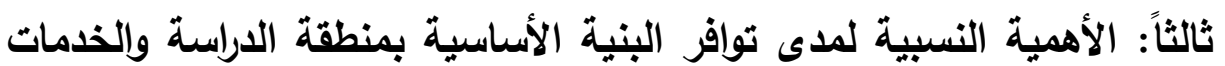

ا- درجة الاستقرار الأمني: تبين من المتغيرات الموضحة بالجدول (ع) أن درجة الاستقرار

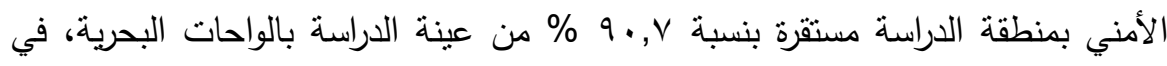

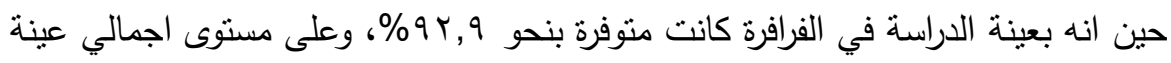

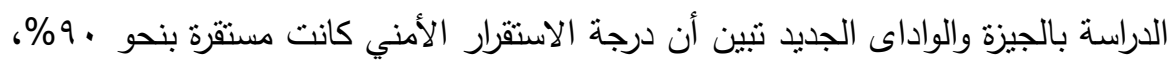

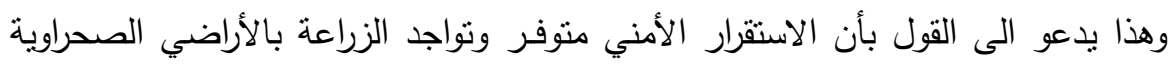

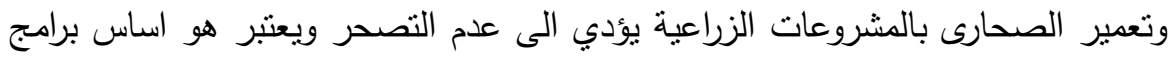
مكافحة التصحر فى مصر ولكنها غير مفعلة الثكل اللازم على مستوى اجمالي العينة في حين على العكس من ذلك في منطقة الدراسة كانت درجة عدم الاستقرار مؤشرا لزيادة 
التصحر بعينة الدراسة حيث من المككن تحول بعض المزارع الى أراض بور أو أنشطة

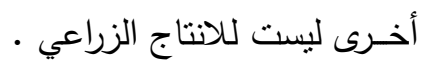

r- خدمات الطرق: لما كانت نواجد خدمات الطرق بالأراضي الصحراوية عاملا مهما ومؤثرا

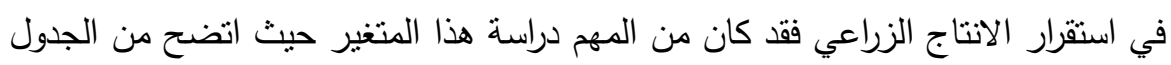

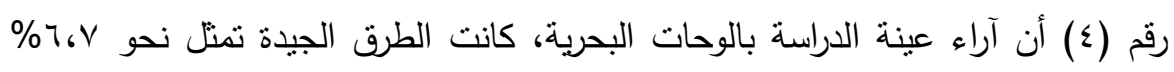

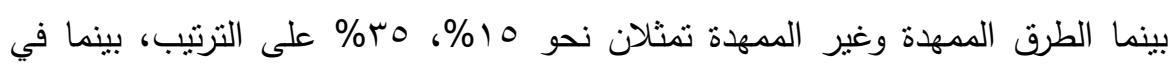

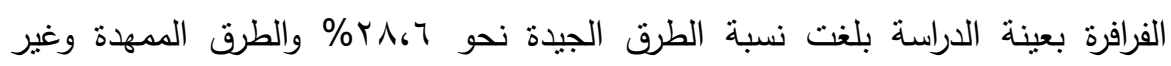

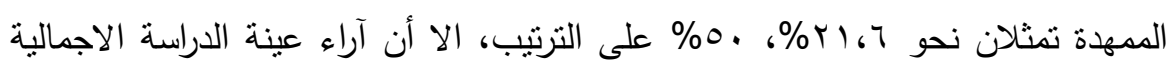

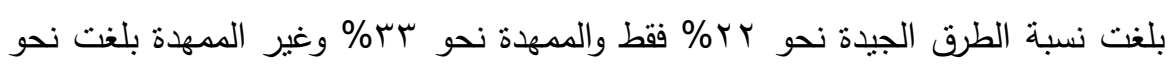

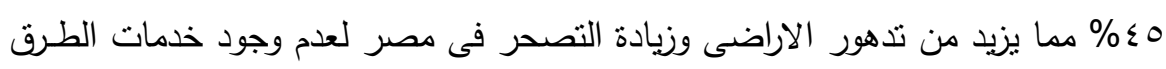

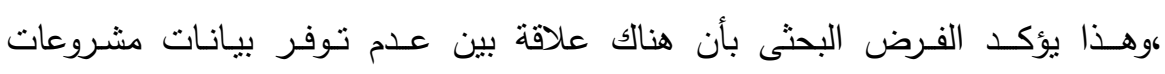

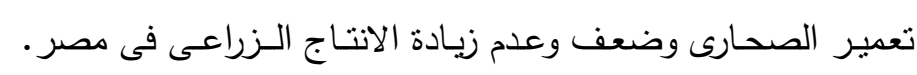

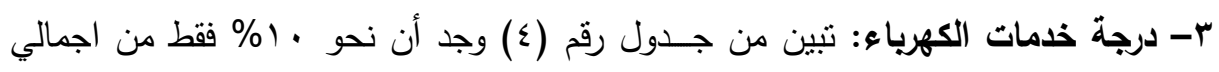

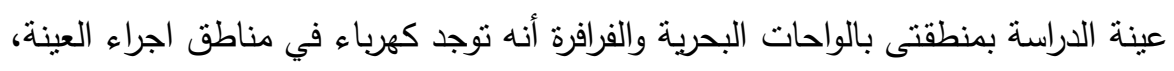

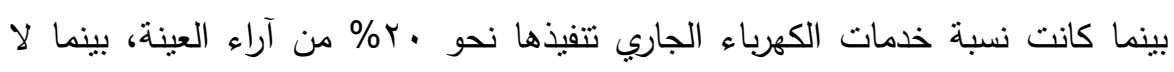

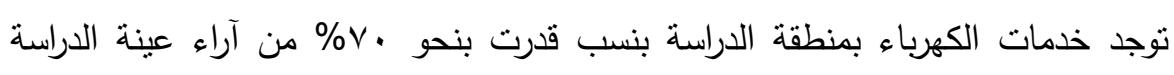
المبحوثين وهذا يساعد على عدم الاستمرار في الانتاج الزراعي نظرا لعدم وجود بدائل

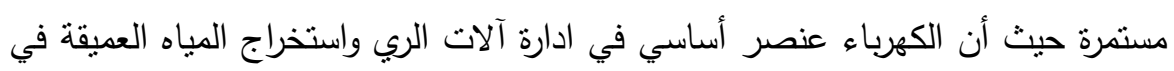
هذه المنطقة مما يزيد من التصحر في الأراضي القابلة للزراعة .

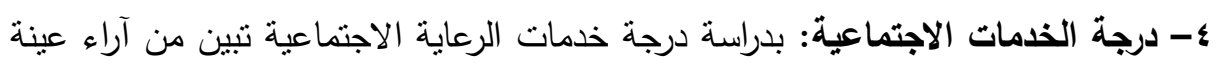
الدراسة أن نحو ، و\% أيضا من اجمالي عينة الدراسة كانت الرعاية الاجتماعية متوفرة

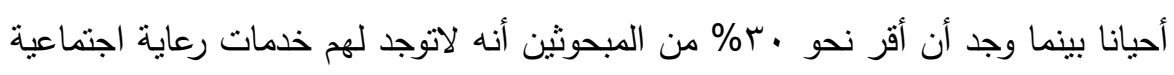

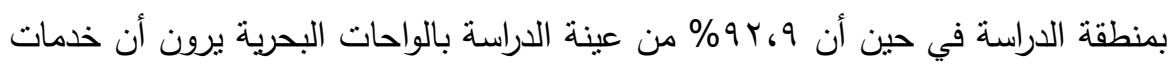

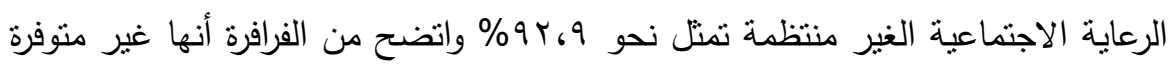

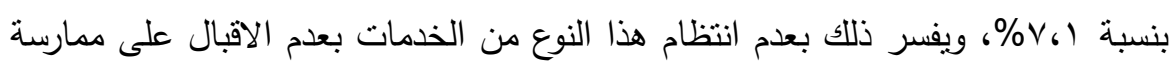

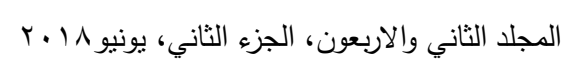


الانتاج الزراعي بالمنطقة مما يزيد من المساحات التي لا تزرع والتي تهمل وتتحول الى

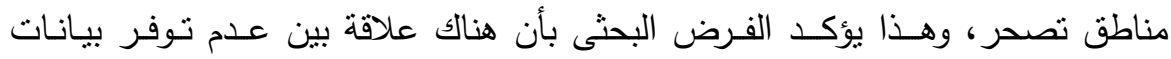

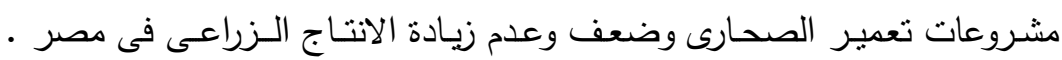

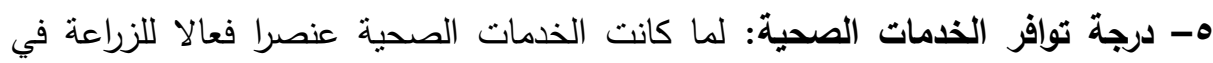

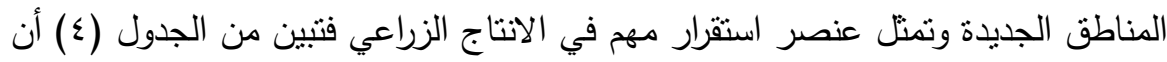

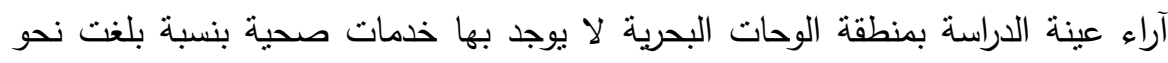

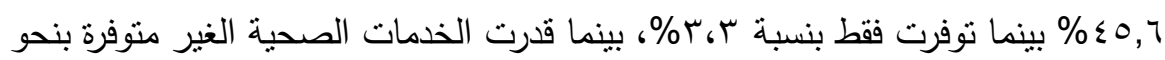

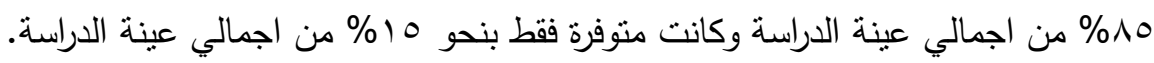

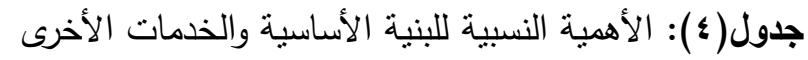

\begin{tabular}{|c|c|c|c|c|}
\hline \multicolumn{2}{|c|}{ الفرافرة } & \multicolumn{2}{|c|}{ الواحات البحرية } & \multirow{2}{*}{ المتغيرات المحافظات } \\
\hline$\%$ & عدد & $\%$ & عدد & \\
\hline $9 r, 9$ & 70 & $9 \cdot, V$ & 0. & مستقرة \\
\hline- & - & - & - & غير مستقرة \\
\hline Y^, T & $r$. & $7, V$ & $\bar{r}$ & طرق جيدة \\
\hline Y), & 10 & 7. & 11 & طرق ممهذة \\
\hline 0. & ro & (T, & 1. & طرق غير ممهدة \\
\hline $\mathrm{V}, 1$ & 0 & $17, V$ & 0 & توجد \\
\hline$T \leqslant, r$ & 1. & Tr, & 1. & جارى الإنشاء \\
\hline$\vee \wedge, 7$ & 00 & 0. & 10 & لا توجد \\
\hline $9 r, 9$ & 70 & $17, V$ & 0 & غير منتظمة \\
\hline $\mathrm{v}, 1$ & 0 & $\Gamma \wedge, r$ & TO & لا توجد \\
\hline$r$. & $1 \leq$ & $r, r$ & 1 & متوفرة أحيانا \\
\hline A. & 07 & $\{0,7$ & rq & غير منوفرة \\
\hline $\mid V, 1$ & IT & 1. & $\bar{r}$ & توجد دائما \\
\hline $1 \wedge, 7$ & 14 & $Y 7, V$ & $\Lambda$ & احيانا \\
\hline$T \xi, \Gamma$ & $\leqslant 0$ & Tr, & 19 & خدمات خاصة \\
\hline
\end{tabular}

צ- الخدمات الأمنية والارشادية: من خلال الدراسات والبحوث السابقة طبقا للسياسة العامة الزراعية في مصر أن درجة نوافر الخدمات الأمنية والارشادية الزراعية من أهم عوامل

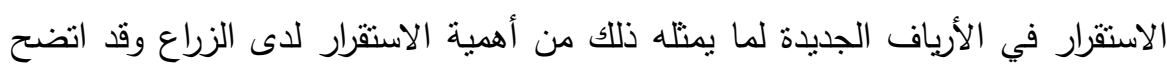

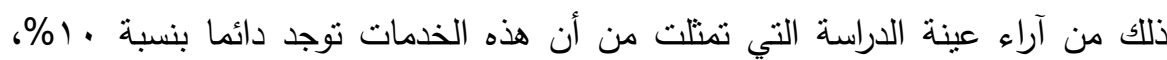
388

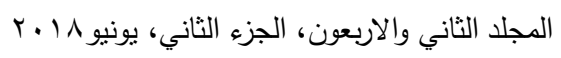




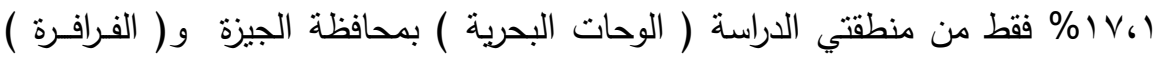

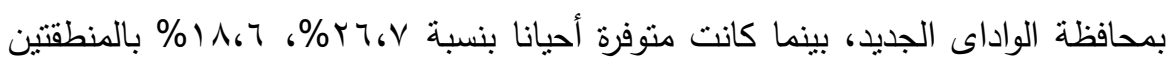
على الترتيب في حين أن هناك خدمات خاصة من قبل أصحاب المزارع وعلى نفقتهم

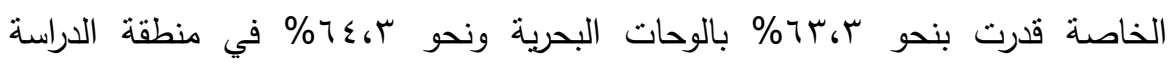
بالفرافرة، وهـذا يـؤكـد عـدم قيام الدولة بأداء الخـدمات الأمنية والارشادية الزراعية

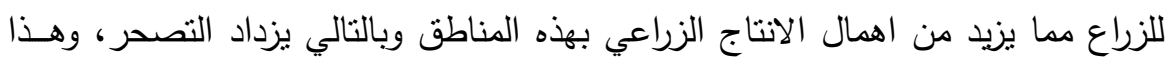

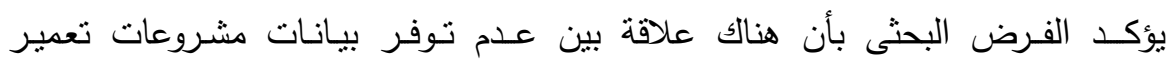

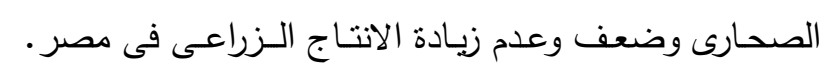

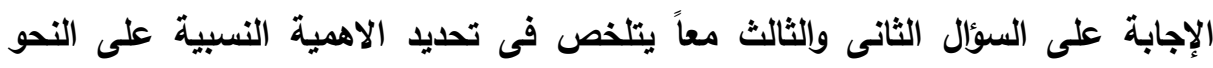
التالى : الاجائ

أولاً: الأهمية النسبية للمشاكل والمنافع البيئية بعينة الدراسة: تتتاول متغيرات

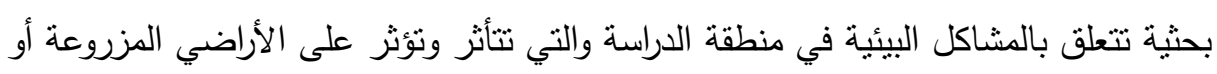

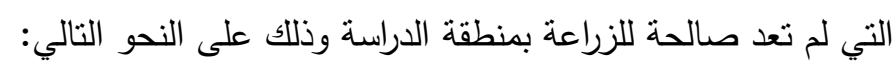

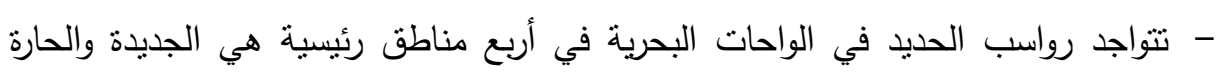
وناصر وجبل غرابي وتتكون هذه الرواسب بصفة أساسية من أكاسيد الحديد المائية

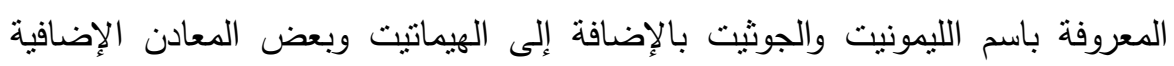
الأخرى. - عدم الاهتمام بتجهيز الخامات و دراسة الجدوى الغير كاملة، مما يدل على ان التكلفة والعائد لمشروعات تعمير الصحارى غير محددة لعدم وجود دراسات جدوى اقتصادية وبيئية واضحة المعالم الاقتصادية والرؤيا اللبيئية.

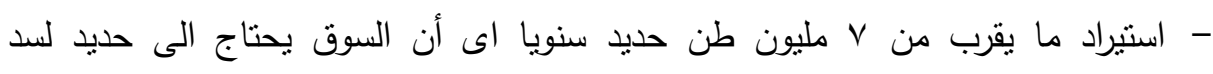

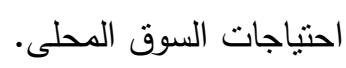
- المنافع البيئية جوا وأرضا ومياه - ونظرا لمناخ الواحات البحرية المعتدل والمنميز ، فهى

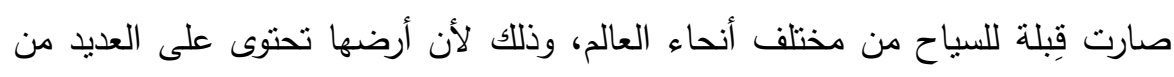
الآثار، ولذلك فهى تُعد من الاماكن الأثرية والسياحية فى مصر وخصوصا السياحات 
القصيرة والسياحات الترفيهية والجوية والتى تكون من أجل العلاج، وأيضا من المنافع البيئة الأرضية بأنها تحتوى أرضها على خام الحديد، وتعتبر الآن المصدر الوحيد لإمداد

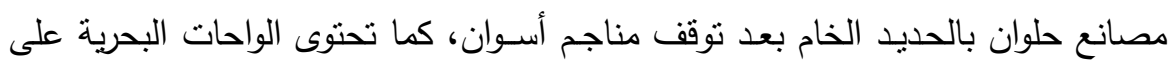
عيون كبرينية تعود على بالنفع من أجل العلاج • فتعود بالنفع على السياحة الخدمية

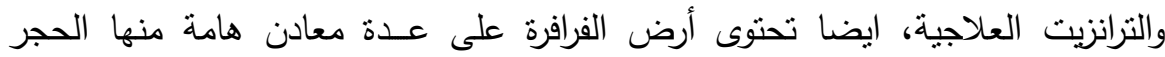

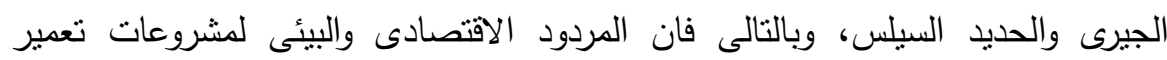
الصحارى بمصر مهر بسبب ايضا عدم دراسات جدوى اقتصادية وبيئية لهذه المشروعات من قبل الدولة.

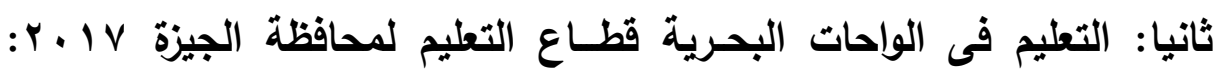
ويوضح الجدول التالى رقم 0 تصنيف التعليم بأنشاله المختلفة فى الواحات البحرية بمحافظة الجيزة وكذلك الفرافرة بمحافظة الوادى الجديد على النحو النالى: جـدول(ه): الأهمية النسبية للتعليم بمنطقة الدراسة

\begin{tabular}{|c|c|c|}
\hline عدد بالقـراصـرة & عداد بالواحسات & انوع المدرسه \\
\hline لا يوجذ & $r$ & حضانة نموذجية تتبع الجمعية الثُرعية \\
\hline III & YT & أبتذأئى \\
\hline$\Pi$ & 7 & أغدادى \\
\hline$T$ & - & نانوى زراعى \\
\hline- & $T$ & تانوى تجارى \\
\hline T & $\bar{Y}$ & ثنانوى صناعي \\
\hline$T$ & $T$ & لمانوى عام \\
\hline لاليوجد & $\varepsilon$ & معاهـد ازهرية اعـدادى وتثانوى \\
\hline
\end{tabular}

أما الاجابة على السؤال الخامس يتلخص فى تحديد التحليل الكىى لمتغيرات الدراسة على النحو التالى: - التى

\section{ولاً: التحليل الكمى لمتغيرات الدراسة:}

- تحليل الإِتياط: يتتاول هذا الجزء من الدراسة استعراضا للنتائج التحليلية التي نم التوصل

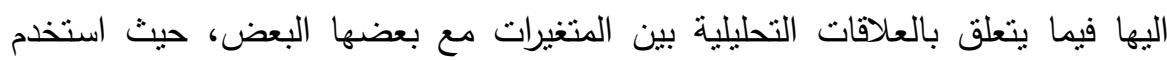

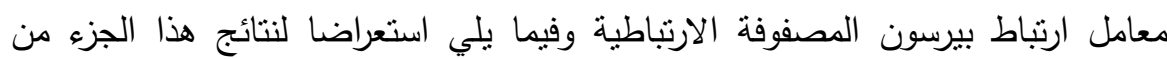


ثانياً: العلاقات الارتباطية حيث يتبين من جـدول (؟) النتائج التالية: - يوجد ارتباط معنوي موجب بين الحيازة الزراعية من الأراضي الصحراوية المزروعة بمنطقتي الدراسة وبين متغير نوع التربة ومتغير نوع المزروعات ومتغير درجة التغيرات

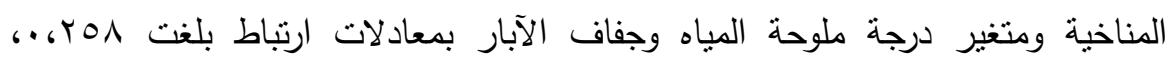

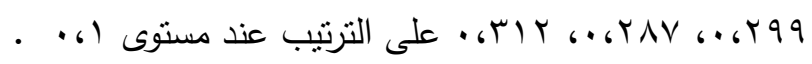

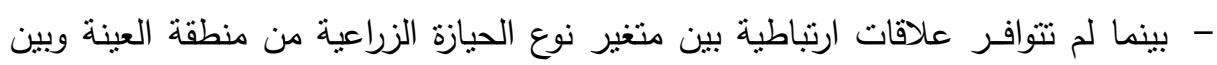

$$
\text { باقي متغيرات الدراسة. }
$$

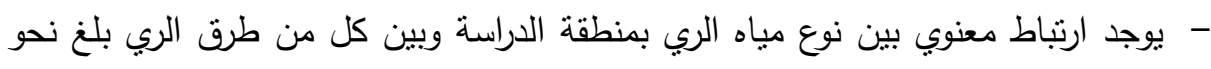

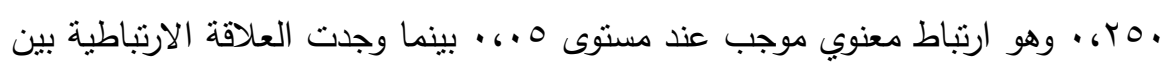

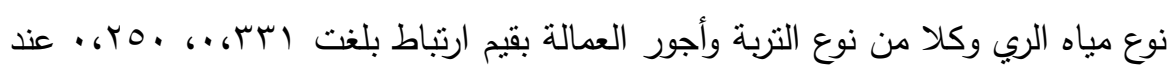

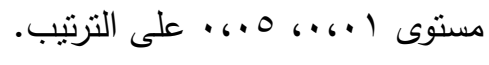

- وجدت علاقات ارتباطية بين متغير تكاليف ري الفدان من الأراضي الصحراوية بمنطقة الدراسة وبين كلا من نوع مياه الري وتكاليف ري الفدان ومتوسط تكاليف انتاج الفدان

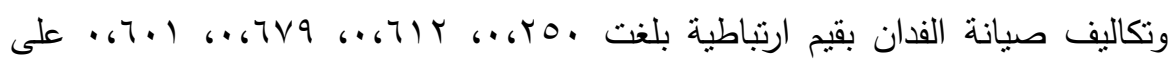

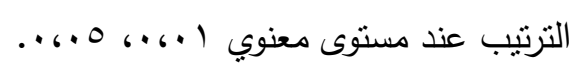

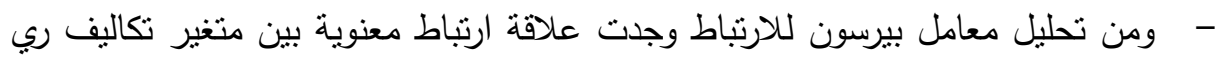

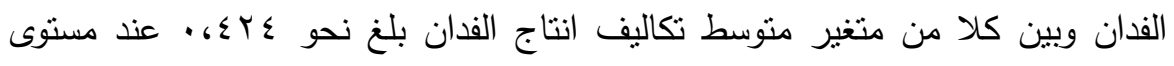

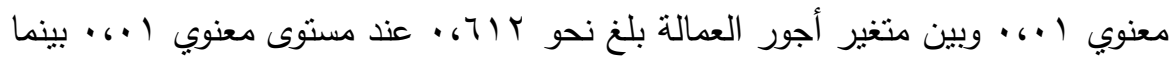
بلغت العلاقة الارتباطية بين متغير تكاليف ري الفدان وبين متغير البنية الأساسية وتوافر

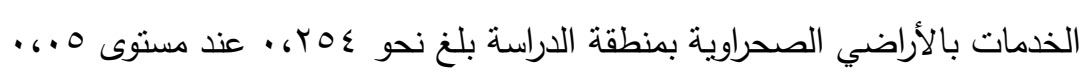

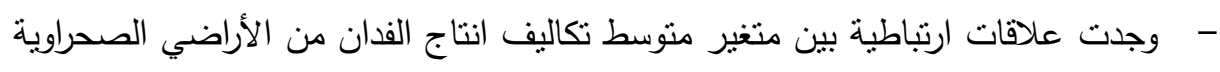

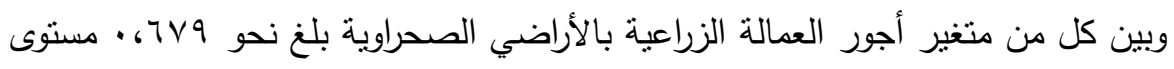

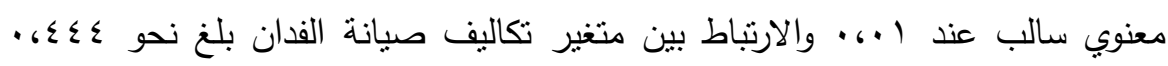

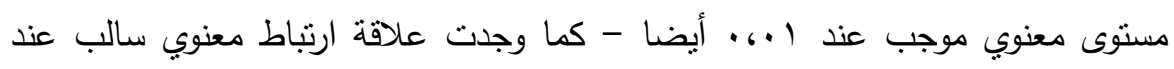

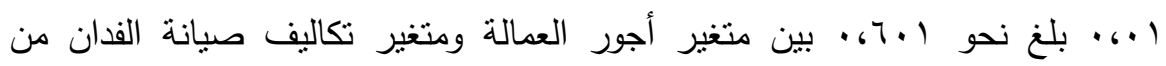

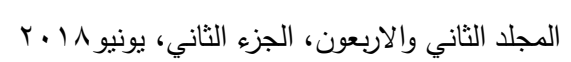


الأراضي الصحراوية بمنطقة الدراسة - كما وجدت علاقات ارتباطية معنوية سالبة عند

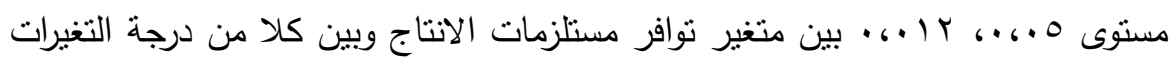

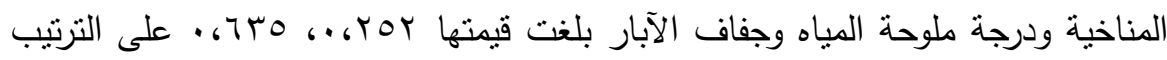
كما اتضح أن هنالك علاقة ارتباط موجبة قوية بين درجة تغير المناخ وبين متغير درجة ولئ

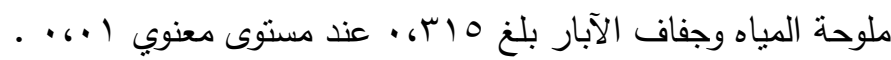

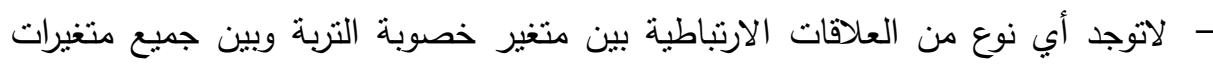

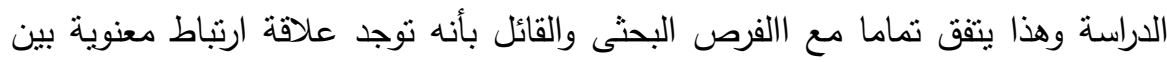
متغير درجة خصوبة التربة وبين جميع المتغيرات البحثية التي تتاولتها الدراسة وهي بهي تكاليف نوع الحيازة الزراعية، نوع مياه الري، طرق الري بالأراضي الصحراوية، تكاليف ري

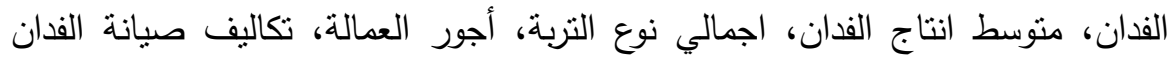

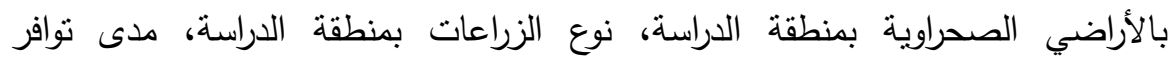

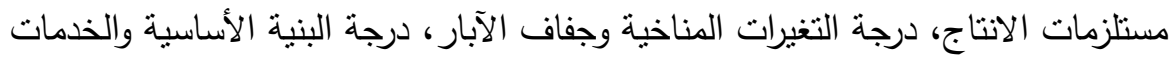

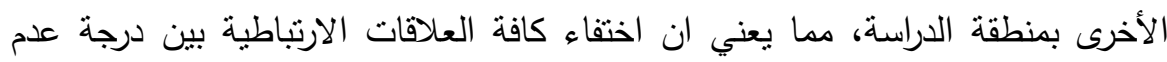

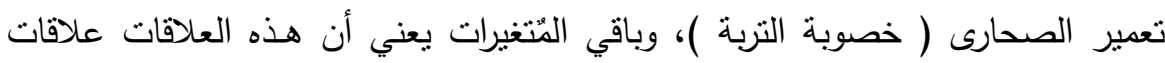
اقترانية غير أصبلة مما يستلزم بالضرورة مزيدا من البحوث والدراسات المسنقبلية. 


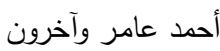

جدول رقم(†): مصفوفة الإرتباط بين المتغيرات المستقلة والمتغير التابع

\begin{tabular}{|c|c|c|c|c|c|c|c|c|c|c|c|c|c|}
\hline $\begin{array}{c}\text { Colum } \\
20\end{array}$ & Colum 18 & Column 17 & Column to & Column 15 & Colum 12 & Columins & Column 7 & Column 6 & Colam 5 & Colmin 3 & Column? & Colum 1 & \\
\hline & & & & & & & & & & & & & Column 1 \\
\hline & & & & & & & & & & & 1 & 4.01033 & Column2 \\
\hline & & & & & & & & & & 1 & 2005258 & 0.066155 & Column 3 \\
\hline & & & & & & & & & & +0.00996 & 0.22974 & 0.152890 & Columnt \\
\hline & & & & & & & & & 1 & 0.05583 & Q.117875 & 0.058752 & Column 5 \\
\hline & & & & & & & & 1 & 0.937816 & 0.083575 & 0.036272 & 0.156488 & Column 6 \\
\hline & & & & & & & & 0.018250 & $0.1261 \%$ & 0.21387 & Q.19142 & 0.075048 & Column? \\
\hline & & & & & & & 1 & 0.016754 & Q.126148 & 0.11204 & 0.187525 & 0.0012 & Column 8 \\
\hline & & & & & & 1 & 0.1464 & 0.124125 & 4.00202 & 0.06267 & 0.024645 & 2.10346 & Column 9 \\
\hline & & & & & 1 & 0.0253 & 0.076341 & 402247 & 4.11482 & 0.683792 & 0.30496 & 4.02233 & Column 12 \\
\hline & & & & & 0.123198 & 0.05605 & 0.030234 & 400947 & 4.M542 & 0.04554 & 0.23224 & 4.1956 & Column 13 \\
\hline & & & & & 0.062872 & 0.079407 & 0.205101 & 0.079969 & 4.09165 & 02100 & 0.256655 & 4.00779 & Column 14 \\
\hline & & & & 1 & 4.16746 & 4.10527 & A21:07) & Q.1972a & 0.0.0936 & 0.075678 & 0.09204 & 0.079139 & Column 15 \\
\hline & & & 1 & 10.06009 & $4.17765^{\circ}$ & 4.19366 & Q. & .01356 & 4.09913 & 0.12528 & 0.002999 & 0.30902 & Column 16 \\
\hline & & 1 & 4.0627 & 0.057311 & $4.110 \mathrm{EA}$ & 4.10397 & 0.04712 & 400107 & 4.12681 & 0.04545 & 2004786 & 0.074108 & Column 17 \\
\hline & 1 & 0.241744 & 0.801546 & 0.380011 & \$.17775 & \$.18217 & 0.012774 & 0.08451 & 4.11279 & 0.14278 & 0.010979 & 0.21052 & Column 18 \\
\hline & 0.061534 & 0.071959 & 4.01172 & Q.40837 & 4.23952 & 0.100556 & 0.051931 & Q. $=6068$ & 0.054328 & 0.16522 & d.11059 & 0.125537 & Column 19 \\
\hline & 020291 & 0.246822 & 4.1.9968 & .0.07237 & a.117604 & \$.02161 & Q.11378 & 0056606 & A.196 29 & Q.181753 & Q.13e4s & s.04177 & Columnzo \\
\hline
\end{tabular}

$$
\text { المجلد الثاني والاربعون، الجزء الثاني، يونيو \ـ ـ }
$$


لذلك فان ما يسمى بالثثرة التخطيطية الحقيقية يجب أن ترمى لتصويب القرار

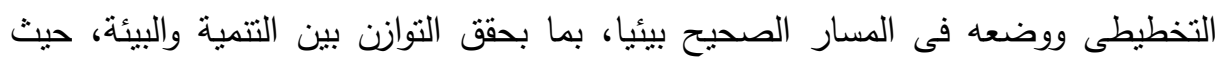
كانت النظرة التقليدية السائدة لأهداف المؤسسات الاقتصادية فى النصف الاول من القرن بهن

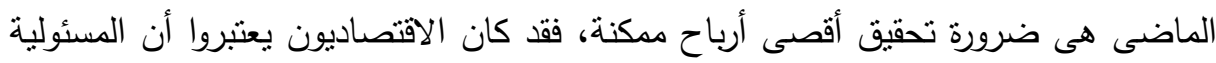

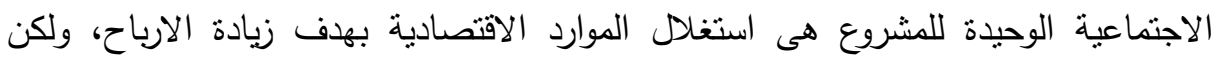

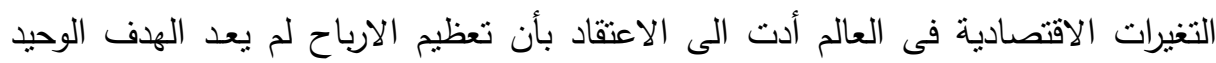

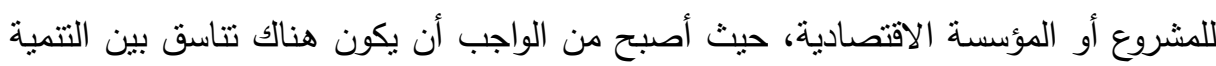
والبيئة عند التخطيط للتنمية.

وعليه فإن سوء إدارة الموارد الطبيعية واستنزافها وما ينتج من مشكلات ومخاطر بيئية

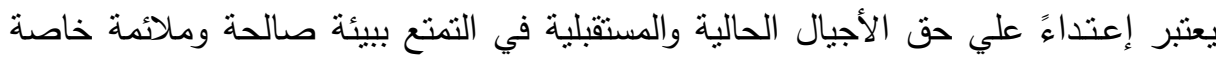
في بلداننا الفقيرة التي تعتمد اعتمادًا كبيرًا علي قاعدة مواردها الطبيعية، إضافة إلي ما تتميز

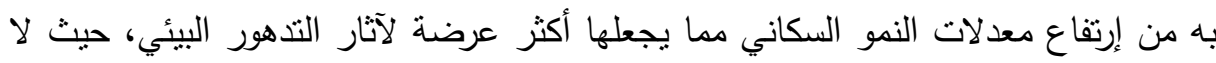
ينشأ ذلك التدهور بفعل المشروعات فحسب بقدر ما ينتج من الآثار التراكمية للممارسات والعمليات الزراعية الصغيرة والعديدة في صورة أنماط سلوكية خاطئة لإدارة النظم الزراعية

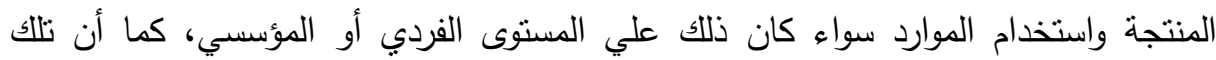

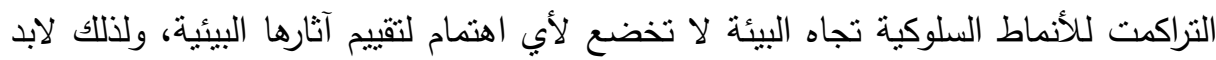

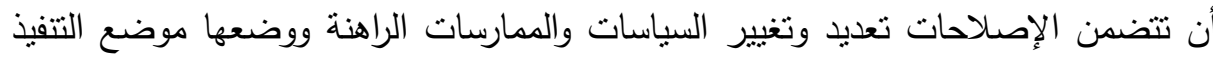
في إطار قدرة المجتمعات علي إعطاء ضوابط وأحكام قيمية لآثار التنهور البيئي وتحمل

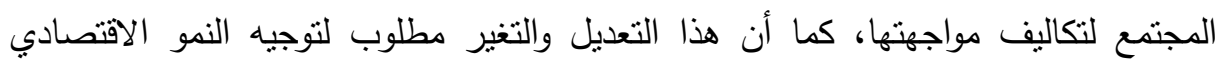

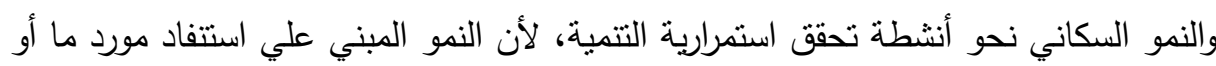
ما يعرف بتكلفة التدهور يختلف تمامًا عن النمو الذي ينتج عن الجهود الإنتاجية، وما لم يكن موليك

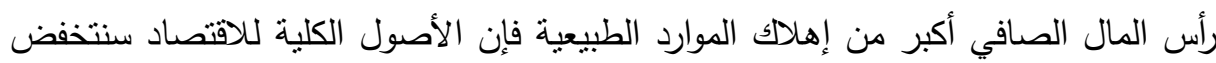

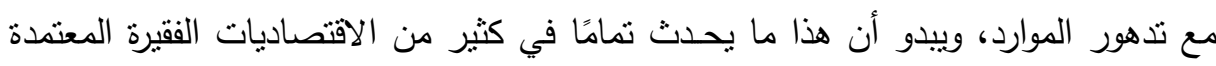

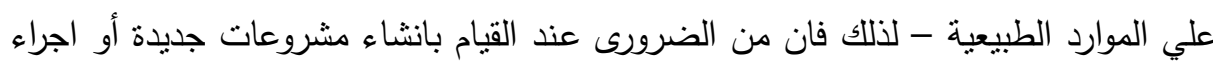

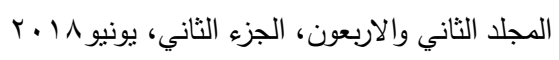


عمليات احلال أو تجديد فى أى من المشروعات أن تتضمن دراسات الجدوى الاقتصادية لهذه

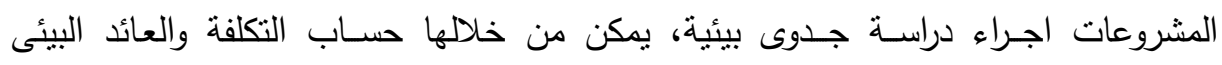

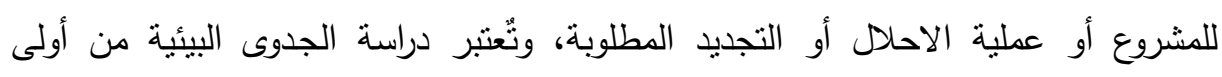

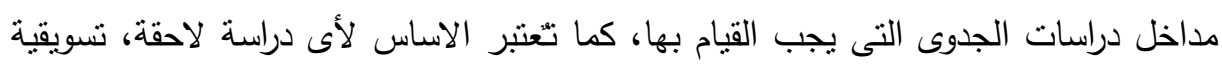

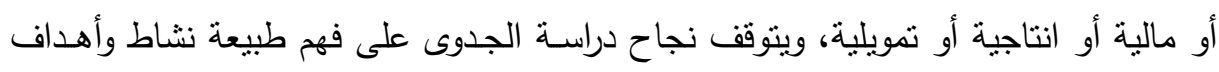

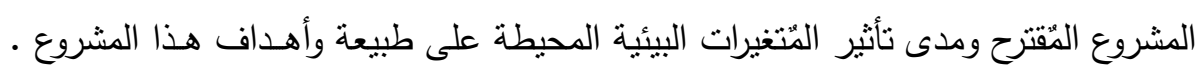

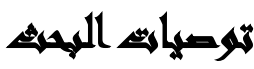

\section{ونستخلص من البحث التوصيات الهامة الاتية:}

- ضرورة إعداد قاعدة معلومات تتعلق بالمصطلحات والمقاييس والموارد المائية ونوع التربة التهية والأنواع النباتية.

- تفعيل مشروعات مكافحة التصحر عن طريق زيادة المساحة الخضراء وحماية البيئة وحدوث نوازن فى البيئة الأيكولوجية لتحقيق التتمية المستدامة.

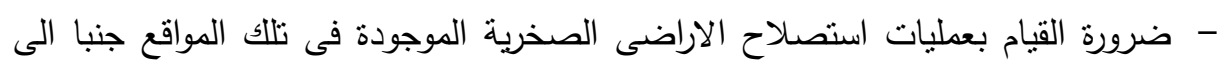
جنب مع تطبيق الية حماية للمراعى من خلال تتظيم اوقات الرعى وفتراتها، فهذا سيؤدى الارفي جعل المنطقة مُنتجة زراعيا، تربتها تتمتع بخصوبة وإنتاجية عالية والى زيادة كثافة الغطاء النباتى الطبيعى وتحسين وجود النباتات المُّنساغة. - يجب أن يسهم تقييم وقياس التلوث البيئى فى وضع معايير لضبط التدهور البيئى، حيث البئ

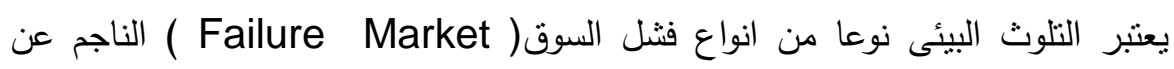
الاستخدام المفرط للموارد سواء فى ظل قوانين تحمى الملكية من عدمه.

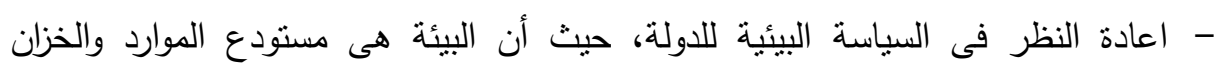
الثنامل لعناصر الثروة الطبيعية المتجددة وغير المتجددة، وتتجلى فى الانظمة المائية والهوائية والتربة والمراعى والغابات والكائنات الحية والانظمة الايكولوجية الداعمة للحباة فى هـــا الكوكب. 
- ضرورة تطوير الانماط والممارسات الزراعية باستخدام الزراعة العضوية، المكافحة

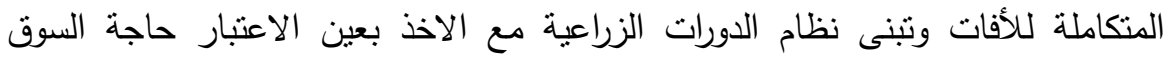
المحلى وتحسين خواص التربة، فعلى سبيل المثال يمكن زراعة المحاصيل البقولية، وقلبها فى الارض، كما يمكن اضافة الاسمدة العضوية المخمرة للتربة، وهذا سيؤدى الى التقليل

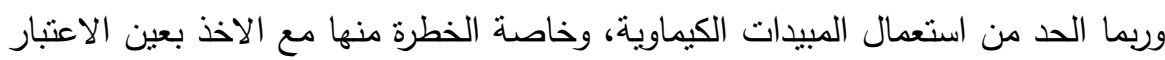

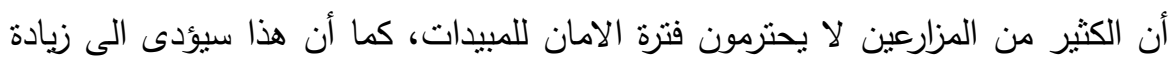

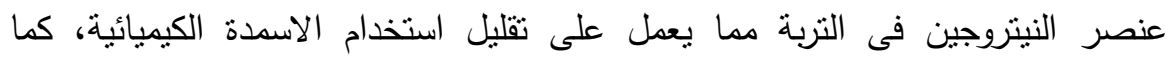
سيؤدى الى زيادة تماسك حبيبات التربة ومنع انحرافها.

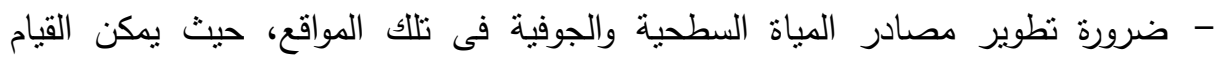

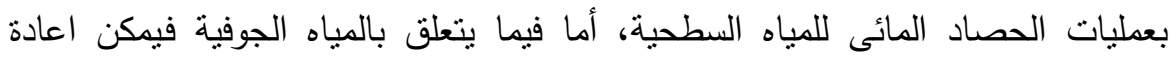

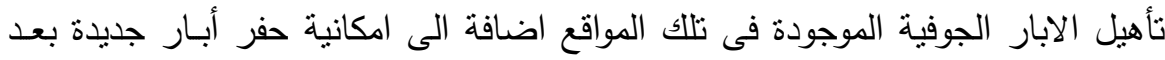

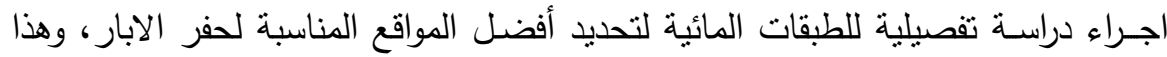

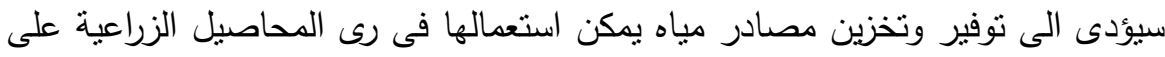

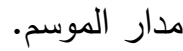
- ضرورة تتريع القوانين التى تختص بحماية المراعى العامة والخاصة وتوضيح عقوبات انتهاك هذه القوانين، وذللك من أجلـل المساعـدة فى اسـتـامة الموارد الطبيعية.

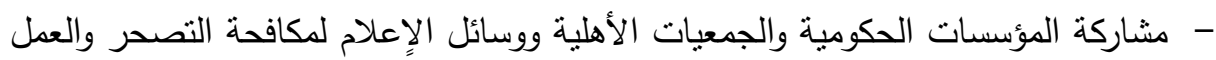
على تفعيل واقامة مشروعات قومية لتعمير الصحارى فى مصر وزيادة الرقعة الزراعية والانتاجية لزيادة الدخل القومى وزيادة التصدير وتقليل الاستيراد والعمل على استخدام

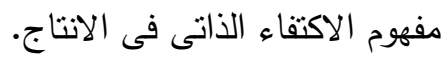
- القضاء على حركة الكثبان الرملية النشطة باستخدام الطرق الميكانيكية والبيولوجية. الإدارة السليمة والمتكاملة للبيئة الصحراوية من خلال المحافظة على التتوع الحيوى من مياه

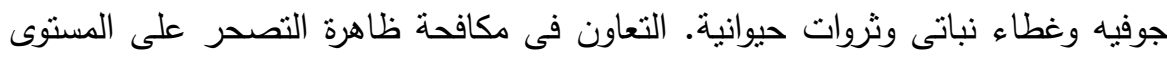

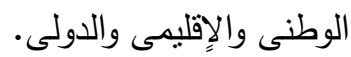




\section{المراني}

أسعد الفقى (ع ا يونيو 10 • بم): أراضى الواحات البحرية حقائق تحتاج الى تكاتف، ط :

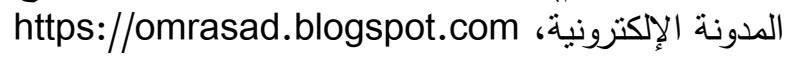

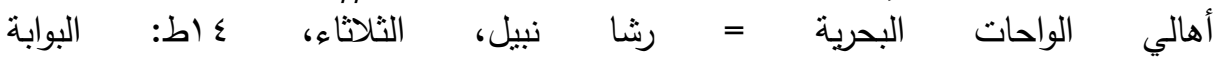

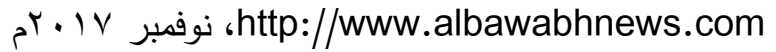

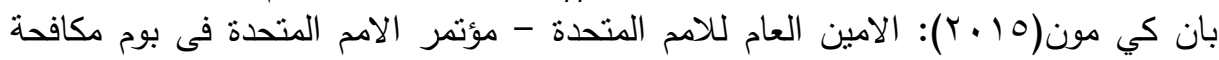

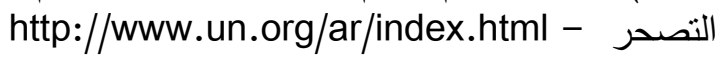

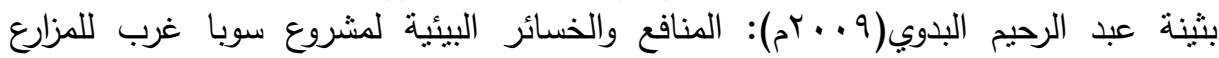

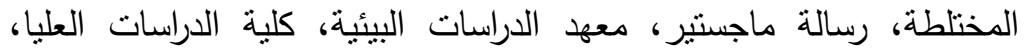

$$
\text { جامعة الخرطوم }
$$

تقرير هيئة الامم المتحدة لمكافحة التصحر ، اليوم العالمى لككافحة التصحر، Vا ليوينو

$$
\text { r. } 10
$$

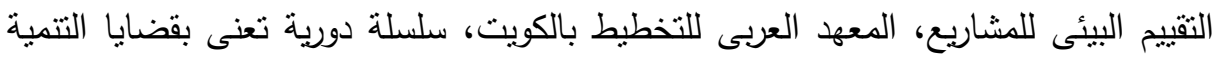

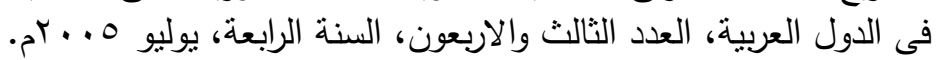

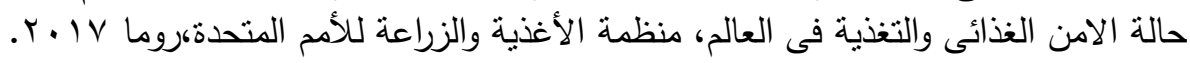

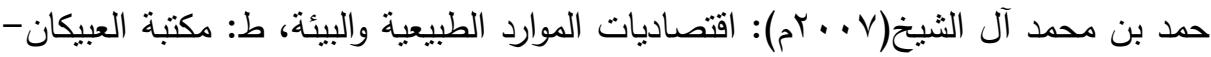

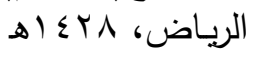

أحمد فخرى، تحقيق: شوقى عبد القوى عثمان، كتاب الصحراوات المصرية، واحات البحرية

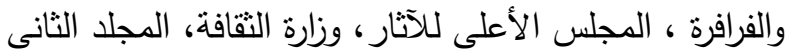

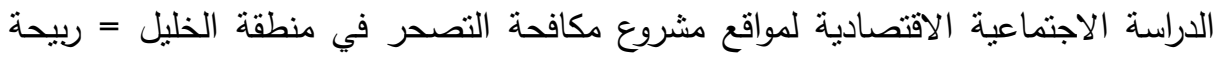

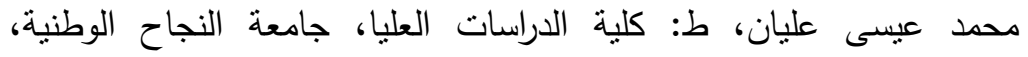

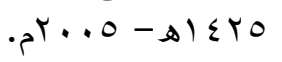

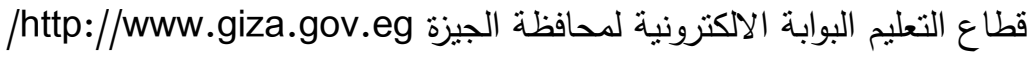
مركز بحوث الصحراء، وزارة الزراعة، التقرير الوطنة التهني الأول لمكافحة تدهور الأراضي

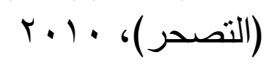

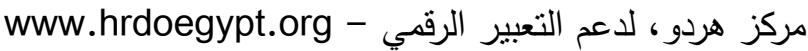

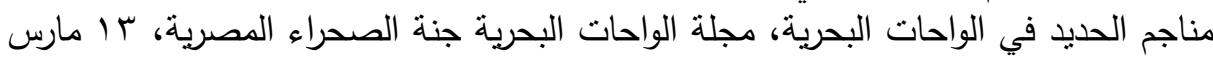

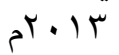

منظمة الأغذية والزراعة، الأمم المتحدة، إستنيراتيجية التتمية الزراعية فى مصر حتى العام

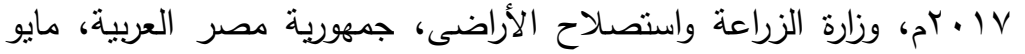

$$
\text { بs }
$$

المؤتمر الدولى بعيئة الأمم المتحدة فى سبتمبر .... F م

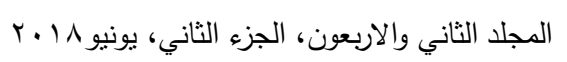


هيئة الأمم المتحدة(r . . rم): " سياسات برنامج الأمم المتحدة للبيئة لمعالجة المشاكل البيئية

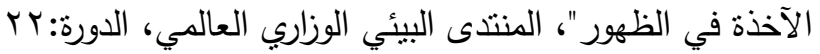

Assessing Land Degradation and Desertification Using Vegetation Index Data: Current Frameworks and Future Directions

Connecting Community Action And Science To Combat Desertification: Evaluation Of A Process

Ferrara, A. (2010): Cost-Benefit Analysis of Multi-Level Government: The Case of EU Cohesion Policy and US Federal Investment Policies, London and New York: Routledge.

Folland, Sherman, Allen C. Goodman and Miron Stano(2007): The Economics of Heath and Health Care. Fifth ed. Pearson Prentice Hall: New Jersey,. pg 83, 84

From Frame work to Action: The DESIRE Approach to Combat Desertification-

Monitoring implementation of desertification combating plan using geomatics - A case study, districts Dhar and Jhabua, Madhya Pradesh. 
أحمد عامر وآخرون

\title{
ANALYSIS OF COST AND BENEFIT FOR RECONSTRUCTION OF THE DESERTS PROJECTS IN EGYPT - A COMPARATIVE STUDY WITH SAUDI ARABIA
}

Amer, A. ${ }^{(1)}$; El-Noby, Thanaa,. ${ }^{(2)}$ and Abd El- Sadeek, O. A. ${ }^{(3)}$

1) Faculty of Commerce 'Ain Shams University, 2) Faculty of Agriculture, ' in Shams University 3) Arab Academy of Advanced Sciences and Technology

\begin{abstract}
The current study was conducted to shed light on the problem of desert reconstruction projects in Egypt in order to identify the strengths and weaknesses of the strategies of desertification control projects in Egypt and the possibility of identifying the economic and environmental benefits of the deserts projects in Egypt using the cost and return of these programs. Saudi Arabia. The descriptive, quantitative and analytical methods were used. The research was based on the field method. The random sample was selected with a total of 100 units. (50) units in Al-Wahat Al-Bahariya area in Al-Giza governorate, and the second number (50) units in Al-Farafra area in the New Valley Governorate. The field questionnaire was used as a tool to collect the study data in the personal interview with the respondents of the farmers who distributed sand lands and rocky lands ،Where the research reached an important result is that one of the most important reasons for the non-reconstruction of the deserts in Egypt, there is a relationship between the lack of data for reconstruction projects deserts and the weakness and non-increas of agricultural production in Egypt, The research recommended the need to resist and combat desertification through the reconstruction of the deserts and by increasing the green area, protecting the environment and achieving a balance in the ecological environment for development. The study recommended the

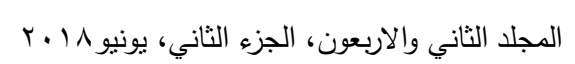


need to achieve the goal of neutralizing land degradation and to be a top priority to meet our requirements and develop sustainability. And recommended the importance of comprehensive cooperation to restore and rehabilitate degraded lands and contribute to the achievement of the goals of sustainable development. The aim of this strategy is to strengthen cooperation between Arab and African countries in order to build an infrastructure based on "green economy and reduce carbon emissions" in cooperation with the neighboring countries related to the recommendation of the research proposal for the current study. The need for "sustainable Arab-African cooperation" called SAAC "Sustainable Arab-African Cooperation ." 